\title{
Injectable and magnetic responsive hydrogels with bioinspired ordered structures
}

\author{
Sandra Araújo-Custódio, ${ }^{a, b}$ Manuel Gomez-Florit, ${ }^{a, b}$ Ana R. Tomás, ${ }^{a, b}$ Bárbara B. Mendes, ${ }^{a, b}$ \\ Pedro S. Babo, ${ }^{a, b}$ Suzanne M. Mithieux, ${ }^{c, d}$ Anthony Weiss, ${ }^{c, d, e}$ Rui M. A. Domingues, ${ }^{* a, b, f}$ Rui L. \\ Reis $^{a, b, f}$ and Manuela E. Gomes $* a, b, f$
}

a3B's Research Group, I3Bs - Research Institute on Biomaterials, Biodegradables and Biomimetics, University of Minho, Headquarters of the European Institute of Excellence on Tissue Engineering and Regenerative Medicine, AvePark, Parque de Ciência e Tecnologia, Zona Industrial da Gandra, 4805-017 Barco, Guimarães, Portugal;

'ICVS/3B's - PT Government Associate Laboratory, Braga/Guimarães, Portugal;

${ }^{\mathrm{c}}$ Charles Perkins Centre, The University of Sydney, Camperdown, New South Wales 2006, Australia

${ }^{\mathrm{d} S c h o o l ~ o f ~ M o l e c u l a r ~ B i o s c i e n c e, ~ T h e ~ U n i v e r s i t y ~ o f ~ S y d n e y, ~ S y d n e y, ~ N e w ~ S o u t h ~ W a l e s ~ 2006, ~}$ Australia.

'Bosch Institute, The University of Sydney, Sydney, New South Wales 2006, Australia.

${ }^{f}$ The Discoveries Centre for Regenerative and Precision Medicine, Headquarters at University of Minho, Avepark, 4805-017 Barco, Guimarães, Portugal

Corresponding Authors: *megomes@i3bs.uminho.pt; *rui.domingues@i3bs.uminho.pt

Keywords: Magnetic nanoparticles, Magnetic alignment, Anisotropic hydrogels, Ordered tissues 


\begin{abstract}
Injectable hydrogels are particularly interesting for applications in minimally invasive tissue engineering and regenerative medicine strategies. However, the typical isotropic microstructure of these biomaterials limits their potential for the regeneration of ordered tissues. In the present work, we decorated rod-shaped cellulose nanocrystals with magnetic nanoparticles and coated these with polydopamine and polyethylene glycol polymer brushes to obtain chemical and colloidal stable nanoparticles. Then, these nanoparticles $(0.1-0.5$ wt.\%.) were incorporated within gelatin hydrogels, creating injectable and magnetically responsive materials with potential for various biomedical applications. Nanoparticles alignment within the hydrogel matrix was achieved under exposure to uniform low magnetic fields $(108 \mathrm{mT})$, resulting in biomaterials with directional microstructure and anisotropic mechanical properties. The biological performance of these nanocomposite hydrogels was studied using adipose tissue derived human stem cells. Cells encapsulated in the nanocomposite hydrogels showed high rates of viability demonstrating that the nanocomposite biomaterials are not cytotoxic. Remarkably, the microstructural patterns stemming from nanoparticles alignment induced the directional growth of seeded and, to a lower extent, encapsulated cells in the hydrogels, suggesting that this injectable system might find application in both cellular and acellular strategies targeting the regeneration of anisotropic tissues.
\end{abstract}




\section{Introduction}

In the human body, many tissues such as cartilage, skeletal muscle, corneas, muscles, blood vessels or tendons and ligaments exhibit highly anisotropic mechanical strength and hierarchically ordered composite structures. This anisotropic organization, which play key roles on their

functionality is severely compromised after injury during tissue repair. ${ }^{1}$ Given the importance of extracellular matrix (ECM) and cellular organization in the functionality of these tissues, strategies capable of inducing their native organization during the healing phase in order to minimize scar tissue formation and to recover their function prior to injury are therefore highly demanded. Tissue engineering and regenerative medicine strategies based on injectable hydrogel systems might provide potential minimally-invasive alternatives to locally administer combinations of biodegradable biomaterials, cells and/or bioactive molecules that can potentially promote a functional tissue healing process. ${ }^{2}$ However, and despite their water-rich three-dimensional (3D) structures, which might find similarities with those of biological tissues, most polymeric hydrogels are usually composed of randomly oriented 3D networks with generally low mechanical performance and lack of control over their microarchitecture. ${ }^{3,4}$ These characteristics are major limitations for the regeneration of anisotropic tissues since randomly organized 3D scaffolding biomaterials provide a suboptimal, or even scar-inducing, tissue template that will not restore the key biological and biomechanical functionality of the native tissue. Therefore, the development of injectable hydrogel systems that can adopt an in situ anisotropically aligned microstructure upon administration to provide a biomimetic tissue template for re-establishing the native tissue architecture addresses one of the unmet clinical needs in this field.

The incorporation of nanoparticles into hydrogels produces a class of materials known as nanocomposite hydrogels with improved physical properties or incorporating new functionalities 
that can be advantageously explored in TE applications. ${ }^{5-9}$ The orientation of $1 \mathrm{D}$ or $2 \mathrm{D}$ nanofillers within hydrogel precursor dispersions followed by their subsequent fixation during the gelation process has been explored in recent years to produce hydrogels with anisotropic microstructures and mechanical behavior. ${ }^{10,11}$ The intrinsic properties of magnetic nanoparticles (MNP) are highly attractive to produce this type of biomaterials, particularly when considering injectable systems. ${ }^{12-}$ ${ }^{16}$ The ability to control the spatial distribution and orientation of MNP through remote magnetic fields offers a much wider biomaterial design space, allowing to generate physical anisotropy within 3D hydrogels in both in vitro and in vivo settings. Moreover, the incorporation of MNP into hydrogel systems results in biomaterials with magnetic responsiveness that can be explored as remote actuators for the mechanical stimulation of encapsulated stem cells, potentially promoting their differentiation towards targeted lineages. ${ }^{17-19}$ The collective synergy of these features, typically unavailable in other nanocomposite systems, might contribute to promote a regenerative outcome using minimally invasive TE strategies directed to anisotropic and mechanosensitive tissues such as e.g. muscle or tendons. Recently, a few studies explored the concept of linear alignment of MNP within hydrogel matrices to produce biomaterials with anisotropic properties. ${ }^{10,20}$ For example, superparamagnetic iron oxide nanoparticles were used to align collagen fibers ${ }^{21}$ or rod-shaped microgels ${ }^{19}$ within collagen or fibrin-based hydrogels, respectively, which induced fibroblasts and neurons unidirectional growth. However, although these works indicate the potential of the strategy to engineer anisotropic tissues, the intricate synthesis route of the proposed microgels or the lack of demonstration of e.g., the anisotropic mechanical properties of the bulk hydrogels, suggest that further developments in this field are still highly needed and alternative solutions should be evaluated. 
We have developed a range of nanocomposite hydrogels exploring the intrinsic properties of $1 \mathrm{D}$ cellulose nanocrystals (CNC) ${ }^{22-24}$ Among the inherent properties of these naturally derived rodshaped nanoparticles are their remarkably high strength and stiffness, convenient surface chemistry for easy functionalization and lower toxicity compared to other common nanofillers. ${ }^{25}$ This set of characteristics makes CNC particularly interesting as reinforcement elements and active crosslinkers of hydrogel networks. Interestingly, it has been previously demonstrated that by combining rod or platelets nano/microparticles with MNP it is possible to precisely control their orientation in the 3D space applying low magnetic fields to produce anisotropically reinforced solid polymeric composite materials with defined textures. ${ }^{11}$ We hypothesize that similar approaches can be applied to orient $\mathrm{CNC}$ within injectable hydrogels to produce multifunctional biomaterials with bioinspired anisotropic properties.

Here we present a novel concept where the magnetic manipulation of low concentrations of CNC (0.1-0.5 wt.\%) decorated with MNP (mCNC) within enzymatically crosslinked gelatin-based hydrogels (Fig.1) can be achieved by applying low strength magnetic fields (108 mT). Colloidally stabilized $\mathrm{mCNC}$ with bioinspired surface coatings were newly synthetized as key requirement to enable this concept. The magnetic responsiveness as well as the mechanical and microstructural anisotropy of the injectable nanocomposite hydrogels are demonstrated. The biological performance of selected nanocomposite hydrogels formulations was studied using human adipose tissue derived stem cells (hASCs) and the impact of hydrogels anisotropy on their organization was investigated. 


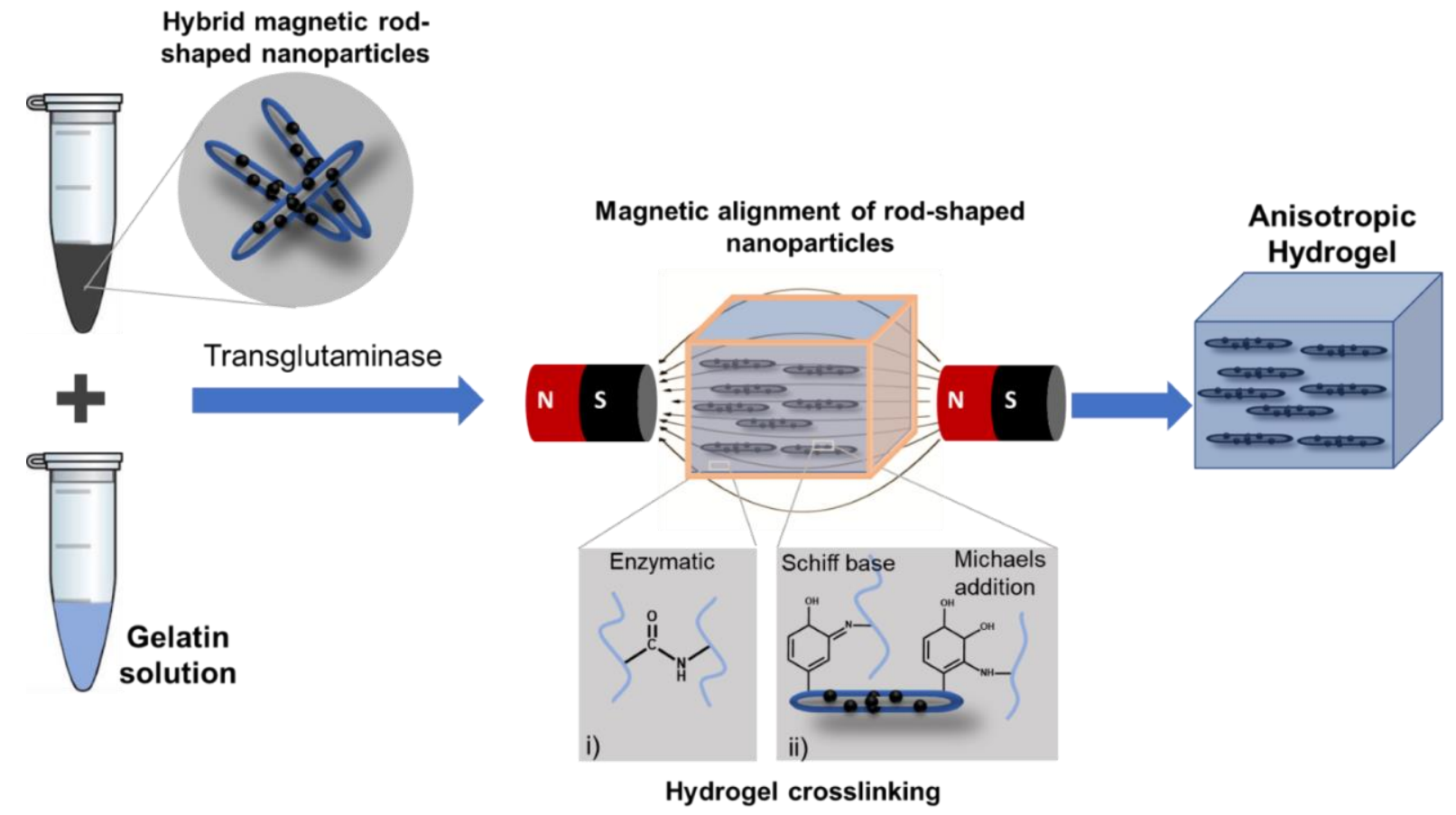

Fig. 1 Schematic representation of anisotropic hydrogel preparation and crosslinking chemistries by i) mTGase and ii) PDA on hybrid magnetic nanoparticles.

\section{EXPERIMENTAL SECTION}

\section{Materials}

Cellulose microcrystalline powder (MCC), sulfuric acid 95-97\%, dialysis tubing cellulose membrane (MWCO 12-14kDa), ammonium hydroxide solution, iron (ii) chloride tetrahydrate 99\%, iron (III) chloride hexahydrate, dopamine hydrochloride, potassium bromide, methoxypolyethylene glycol amine (5000 Da), gelatin from porcine skin (gel strength 300, type A), triton X-100 and phalloidin-tetramethylrhodamine B isothiocyanate (TRITC) was purchased from Sigma-Aldrich, Portugal. The neodymium permanent magnets N52 were obtained from AMF Magnetics, Australia. The microbial transglutaminase was purchased from Ajinomoto, Japan. Silicone squared molds (12 Well Chamber Removable) and $\mu$ Slide Angiogenesis coverslips were 
purchased from Ibidi, Germany. Alpha minimum essential medium ( $\alpha$-MEM), fetal bovine serum (FBS), antibiotic/antimicotic solution, calcein AM, propidium iodide, buffered formalin 10\% (v/v) were purchased from ThermoFisher Scientific, USA. 4',6-diamidino-2-phenylindole (DAPI) was purchased from Biotium, USA.

\section{Synthesis of cellulose nanocrystals}

$\mathrm{CNC}$ were extracted from MCC by sulfuric acid hydrolysis adapting the protocol of Bondeson et al. ${ }^{26}$ First, $42 \mathrm{~g}$ of MCC was mixed with $217 \mathrm{~mL}$ of deionized water in a beaker. The MCC/water suspension was placed in an ice bath to prevent overheating and stirred using a mechanical agitator at $500 \mathrm{rpm}$ for 10 minutes. Then, while stirring, $203 \mathrm{~mL}$ of concentrated sulfuric acid 95-97\% was added dropwise up to a final acid concentration of $62 \mathrm{wt} . \%$. The reaction was performed under

continuous stirring at $60^{\circ} \mathrm{C}$ for 40 minutes. Acid hydrolysis was stopped by adding an excess of cold water ( 5 times the initial volume) and the solution was left to decant at $4^{\circ} \mathrm{C}$. The supernatant was discarded, and the remaining suspension was centrifuged for 10 minutes at $8603 \mathrm{G}$ at $5^{\circ} \mathrm{C}$. After centrifugation, the supernatant was replaced by ultrapure water, and subjected to additional centrifugation cycles until the supernatant became turbid (usually, a total of 3 centrifugation cycles). The resulting suspension was collected and dialyzed against deionized water until neutral pH. After dialysis, the suspension was transferred into beakers and sonicated (VCX-130PB-220, Sonics) for 5 cycles of 5 minutes, using an ultrasound probe at $60 \%$ of amplitude output, under ice cooling to prevent overheating. Then, the cloudy suspension was centrifuged for 10 minutes at $8603 \mathrm{G}$ and $5^{\circ} \mathrm{C}$ to remove big particles that could still remain. Finally, the supernatant containing $\mathrm{CNC}$ was stored at $4^{\circ} \mathrm{C}$ until further use.

\section{Synthesis of CNC decorated with magnetic nanoparticles}


The MNP decorated CNC (mCNC) were synthetized by coprecipitation of $\mathrm{Fe}^{2+}$ and $\mathrm{Fe}^{3+}$ with ammonium hydroxide in the presence of CNC according to the procedure described in ${ }^{27}$ and ${ }^{28}$ with some modifications. First, $50 \mathrm{~mL}$ of a $0.3 \%(\mathrm{w} / \mathrm{v})$ of CNC aqueous suspension was transferred to a triple bottleneck at room temperature (RT), left under a protected nitrogen environment and heated up to $70^{\circ} \mathrm{C}$. Then, MNP salts precursors $\mathrm{FeCl}_{3} \cdot 6 \mathrm{H}_{2} \mathrm{O}$ and $\mathrm{FeCl}_{2} \cdot 4 \mathrm{H}_{2} \mathrm{O}$ were added to the CNC solution at $12 \mathrm{mM}$ concentration and a molar ratio of $2 / 1\left(\mathrm{Fe}^{3+} / \mathrm{Fe}^{2+}\right)$, and left to stirring for 2 hours. $100 \mathrm{~mL}$ of ammonium hydroxide solution was added to the $\mathrm{CNC} /$ iron salt solution and the reaction was carried for 60 minutes under vigorous continuous stirring. After reaction, the resulting precipitate was subjected to magnetic decantation using a permanent magnet. Then, centrifugation cycles of 10 minutes, $8603 \mathrm{G}$ at $5^{\circ} \mathrm{C}$ were performed and washed with deionized water (DI) until reaching a neutral $\mathrm{pH}$. Finally, the resulting $\mathrm{mCNC}$ were suspended in ultrapure water.

\section{Synthesis of polydopamine coated $\mathrm{mCNC}$}

Polydopamine coated $\mathrm{mCNC}$ (pda-mCNC) were synthesized according to Shi Z. et al. ${ }^{29}$ A $0.2 \%$ $(\mathrm{w} / \mathrm{v})$ suspension of $\mathrm{mCNC}$ was dispersed in tris base buffer $10 \mathrm{mM}$ at $\mathrm{pH}=8.5$ and sonicated using ultrasonic processor at $40 \%$ of amplitude output. Then, dopamine hydrochloride was added to the suspension in a 2:1 weight ratio in respect to the mass of $\mathrm{mCNC}$ and left stirring overnight at $\mathrm{RT}$. The resulting suspension was centrifuged $\left(10\right.$ minutes at $8603 \mathrm{G}$ and $\left.5^{\circ} \mathrm{C}\right)$ and washed with DI water.

\section{Synthesis of PEG stabilized nanoparticles}

Methoxypolyethylene glycol amine $\left(\mathrm{mPEG}-\mathrm{NH}_{2}\right)$ coated pda-mCNC (peg-mCNC) were prepared based on the work by Liu. J. et al. ${ }^{30}$ and Zhon X. et al. ${ }^{31}$ pda-mCNC were first suspended in tris base buffer $(10 \mathrm{mM}, \mathrm{pH}=8.5)$ at a final concentration of $0.2 \%(\mathrm{w} / \mathrm{v})$. Then, $\mathrm{mPEG}-\mathrm{NH}_{2}$ was 
added to the suspension in a 2:1 ratio (mPEG-NH 2 :mass of nanoparticles), and left stirring for 150 minutes at RT. Hereafter, the suspension was extensively dialyzed against ultrapure water for two days.

\section{Characterization of nanomaterials}

\section{Atomic force microscopy (AFM)}

AFM was used to determine the nanoparticles size and size distribution. Drops of the diluted nanoparticle solutions with concentration of $0.0015 \%(\mathrm{w} / \mathrm{v})$ were deposited on freshly cleaved mica discs and left to adsorb for 15 minutes, after which the excess of liquid was removed. The samples were left to dry in an exicator overnight and were imaged in tapping mode (Dimension Icon, Bruker) with a range of $\mathrm{xy}-1 \mathrm{~nm}$ to $90 \mu \mathrm{m}$. The particles dimensions (length and height) and size distribution were determined with Gwyddion software.

\section{Transmission electron microscopy (TEM) and scanning TEM (STEM)}

The morphology and distribution of the produced nanoparticles were analyzed by STEM (Auriga Compact, Zeiss). For this purpose, drops of the diluted suspensions (0.0015 wt.\%) were placed in TEM grids (Carbon Type B, 400M Cu, Monocomp), left to dry for 15 minutes and washed in ultrapure DI water. The images were collected with an acceleration voltage from 25 to $30 \mathrm{kV}$. For TEM (JEOL 2100) analysis, peg-mCNC were dropped on ultrathin carbon on lacey carbon on 400 mesh Cu-grids (UC-A lacey 400 mesh $\mathrm{Cu}$, Tedpella) and images acquired at $80 \mathrm{kV}$.

\section{Magnetic Properties}

The magnetic properties of the nanoparticles and hydrogels where assessed using a superconducting quantum interference device magnetometer (SQUID-VSM, Quantum Design). The samples were freeze-dried and analyzed at RT under a magnetic field up to $20 \mathrm{kOe}$. 


\section{Development and characterization of nanocomposite hydrogels}

A 10 wt.\% gelatin solution was prepared in $0.1 \mathrm{X}$ phosphate buffered saline (PBS) for 2 hours at $70^{\circ} \mathrm{C}$ and then cooled to $37^{\circ} \mathrm{C}$. Microbial transglutaminase (mTGase) solution was prepared in PBS at a concentration of $20 \mathrm{wt} . \%$. peg-mCNC were dissolved in ultrapure water at different concentrations $(0,0.2,0.4,0.6$ and $1.0 \mathrm{wt} . \%)$ and dispersed with an ultrasonic processor $(40 \%$ amplitude, 60 seconds). To prepare the final isotropic nanocomposite hydrogels, the gelatin solution at $37^{\circ} \mathrm{C}$ was mixed in a $1: 1(\mathrm{v} / \mathrm{v})$ ratio with the peg-mCNC suspensions and $\mathrm{mTGase}(15$ U/g gelatin). The resulting solutions consisting of $5 \mathrm{wt} . \%$ gelatin and $0,0.1,0.2,0.3$ and $0.5 \mathrm{wt} . \%$ peg-mCNC were thoroughly mixed by pipetting up and down, injected into silicone squared molds $(6 \times 6 \times 4 \mathrm{~mm})$ and kept at $37^{\circ} \mathrm{C}$ in humid atmosphere for 90 minutes to ensure total crosslinking of the hydrogels. The same procedures were adopted for the preparation of anisotropic hydrogels except that the molds containing the hydrogel solutions were kept under the influence of uniform magnetic field of $108 \mathrm{mT}$ in a custom-made magnetic system, composed by two neodymium permanent magnets N52 (Fig. S1). This system, can provide uniform magnetic fields with different strengths depending on the distance between the magnets (see Supporting Information). The magnetic field strength was measured by a Gaussmeter (Hirst Magnetic Instruments).

\section{Scanning Electron Microscopy (SEM) and TEM}

Microstructural morphology and organization of hydrogels were observed by high resolution SEM (JSM-6010LV, JEOL, Japan). Before analysis, hydrogels were freeze-dried, fractured after cooling in liquid nitrogen and sputter-coated with platinum (Cressington Scientific Instruments). The images were collected with an acceleration voltage from 2 to $10 \mathrm{kV}$. SEM images were converted to binary and adjusted with either erode or dialate functions such that all pores could be 
identified as objects with a perimeter. Binary outlines were used for final data generation via the analyze particles function of ImageJ to generate shape description parameters. Prior to processing, thresholds for each image were manually set by measuring the dimensions of the smallest pore. The mean aspect ratio for twenty pores per formulation was calculated.

For TEM analysis of nanoparticles alignment in 3D, isotropic and anisotropic hydrogels with 0.3 wt.\% peg-mCNC were prepared as derived above and solvent exchanged to ethanol with increasing concentrations of $10 \%, 30 \%, 50 \%, 75 \%, 85 \%, 95 \%$ and $100 \%$ ethanol. Hydrogels were then infiltrated successively with different concentrations of Epon (EMbed-812 Kit mit BDMA, EMS). The embedding included 3 setps od propylene oxide $(10 \mathrm{~min})$ followed by successive propylene oxide / resin at 3:1 (2h), 1:1 (overnight at $4^{\circ} \mathrm{C}$ ) and 1:3 (2h) ratio, and finally $100 \%$ resin (2h). The resin was allowed to polymerize at $60^{\circ} \mathrm{C}$ for 3 days. The Epon blocks were sectioned with a RMC PowerTome Ultramicotome. Ultrathin sections were cut with a $35^{\circ}$ Diatom diamond knife. Sections were silver in colour corresponding to a thickness of $60-90 \mathrm{~nm}$. Section were picked up and supported by ultrathin carbon on lacey carbon EM grids. Sections were observed with a JEM-2100 electron microscope, operating a LaB6 electron gun at $80 \mathrm{kV}$ and images acquired with a "OneView" 4k x 4k CCD camera at slight underfocus.

\section{Microstructure analysis by micro-Computed Tomography ( $\mu$-CT)}

The 3D microstructure and architecture of the isotropic and anisotropic hydrogels with 0.2 and 0.3 wt. \% of peg-mCNC were assessed by high-resolution $\mu$-CT analysis (Skyscan 1072, Skyscan, Belgium). Series of 412 two dimensional projections with a resolution of $10.5 \mu \mathrm{m}$ were acquired over a rotation range of $180^{\circ}$ and with a rotation step of $0.45^{\circ}$, by cone-beam acquisition after irradiating the specimens with penetrative X-rays. The acquisitions were performed with a source 
voltage of $33 \mathrm{kV}$ and a current of $197 \mu \mathrm{A}$. The data was reconstructed using the software NRecon (version: 1.6.6.0, Skyscan), and analyzed on CT Analyzer (version 1.4, Skyscan).

The microstructural patterns resulting from the CT reconstructed images of the isotropic and anisotropic hydrogels was evaluated using the directionality plugin from Image $J$ (https://imagej.net/Directionality). For that, $\mu$-CT images were converted to 8-bit grayscale images and the contrast was enhanced for $0.4 \%$ pixels saturation. Then, directionality histograms were obtained.

\section{Swelling assay}

To analyze the swelling behavior of the hydrogels, test specimens without and with $0.1,0.2,0.3$ and $0.5 \mathrm{wt} . \%$ of aligned and random peg-mCNC were prepared in silicone molds, as previously described. After crosslinking, the samples were removed from the molds, left to stabilize at RT for one hour and weighed to determine the initial weight $\left(w_{i}\right)$. Then, the samples were immersed in PBS and incubated at $37^{\circ} \mathrm{C}$ until constant weight was achieved (6 hours). After whipping the excess of water with filter paper, the hydrogels were weighted to determine the final weight $\left(w_{f}\right)$ and the swelling ratio was calculated using the following equation:

$$
\text { Swelling ratio }(\%)=((w f-w i) / w i) \times 100 \%
$$

\section{Rheological analysis}

The selected precursor solutions of gelatin and nanocomposite hydrogels with different pegmCNC content $(0.1,0.2,0.3$ and 0.5 wt.\%) were tested using a rheometer (Kinexus Prot MAL1097376, Malvern). To analyze gelation kinetics, $250 \mu \mathrm{L}$ of the solutions were directly poured onto the bottom Peltier plate preheated at $37^{\circ} \mathrm{C}$ and the gap was adjusted to $1 \mathrm{~mm}$. To prevent evaporation of water from the sample, a thin film of paraffin oil was poured around the perimeter of the sample and a solvent trap was used during the assay. Time-sweep tests were 
performed to monitor variations in storage (G') and loss (G') moduli at $37^{\circ} \mathrm{C}$ during 60 min at a frequency of $1 \mathrm{~Hz}$ and shear strain of $1 \%(\mathrm{n}=3)$. Gelation time was defined as the time at the onset of phase angle drop.

The bulk viscoelastic behavior of isotropic nanocomposite hydrogels was analyzed using a parallel plate geometry $(\varnothing 8 \mathrm{~mm})$ in pre-formed cylindrical hydrogels with $8 \mathrm{~mm}$ diameter and 2 $\mathrm{mm}$ thickness. Oscillatory frequency sweep tests were performed at $37^{\circ} \mathrm{C}$ applying a constant strain amplitude of $1 \%$ (selected within the linear viscoelastic region of the hydrogels) and frequencies between 0.01 and $10 \mathrm{~Hz}$, with an initial preadjusted normal force of $0.5 \mathrm{~N}$. All experiments were performed at least in triplicate and the data represents the average of these tests.

\section{Dynamic mechanical analysis (DMA)}

Viscoelastic measurements were performed using a TRITEC 2000 DMA (Triton Technology, UK), equipped with the compressive mode. The measurements were carried out at RT, for anisotropic hydrogels of 0.3 and $0.5 \mathrm{wt} . \%$, parallel and perpendicularly aligned to the compression force of the DMA equipment. To avoid the possibility that the orientation of the hydrogels in the molds could affect the hydrogel mechanical properties, hydrogels and molds were maintained on the same position and the magnetic system was positioned vertically or horizontally during their production. Moreover, the DMA assay were carried out maintaining the position of both types of hydrogels constant relative to the compression axis. Before analysis, samples were immersed in PBS to reach equilibrium swelling. All the hydrogels were cubical shaped, with height and length of $\sim 6 \mathrm{~mm}$ and a thickness of $\sim 4 \mathrm{~mm}$, measured accurately with a digital caliper. DMA data were obtained during a frequency scan between 0.1 and $10 \mathrm{~Hz}$. The experiments were performed under constant strain amplitude $(40 \mu \mathrm{m})$. At least three different hydrogels were tested for each composition with the same experimental settings. 


\section{Biological performance of nanocomposite hydrogels}

Expansion of human adipose derived stem cells (hASCs). hASCs were obtained from lipoaspirate samples of the abdominal region of patients subjected to plastic surgery, under the scope of previously established protocols with Hospital da Prelada (Porto, Portugal). All procedures were approved by the University of Minho Ethics Committee. hASCs were routinely isolated by enzymatic digestion, and characterized for stemness potential by flow cytometry and

RT-PCR for CD44, STRO-1, CD105 and CD90 markers, as previously reported in Rada, T. et al. ${ }^{32}$ hASCs were maintained in $\alpha$-MEM supplemented with $10 \% \mathrm{FBS}$, and $1 \%$ antibiotic/antimicotic solution at $37^{\circ} \mathrm{C}, 5 \% \mathrm{CO} 2$.

\section{Cell seeding and encapsulation in 3D isotropic and anisotropic hydrogels}

A 10 wt.\% gelatin solution was prepared in $0.1 \mathrm{X}$ PBS supplemented with $25 \mathrm{mM}$ of sucrose in order to control osmotic pressure and improve cell viability in low ionic strength conditions during processing, as described by Carvalho A., et al. ${ }^{33}$ To avoid bacterial growth in biological assays, the nanoparticles suspensions were ultraviolet radiation (UV) treated during 30 seconds, and dispersed by an ultrasonic processor (40 \% amplitude, 60 seconds). Gelatin solution and mTGAse were sterilized using $0.22 \mu \mathrm{m}$ filters (Biotecnomica, Switzerland), and then antibiotic/antimicotic solution was added to achieve a final concentration of $1 \%(\mathrm{v} / \mathrm{v})$. 3D isotropic and anisotropic nanocomposite hydrogels were prepared as described before. Gelatin hydrogels without nanoparticles incorporation were used as additional controls.

For the preparation of cell seeded hydrogels, $100 \mu \mathrm{L}$ of hydrogel-precursor solution was placed into the squared silicone molds. Prior to seeding, all hydrogels were incubated at $37^{\circ} \mathrm{C}$ for 90 minutes to ensure complete crosslinking. Afterwards, cultured cells were detached by 
trypsinization, counted, centrifuged at $300 \mathrm{G}$ for 5 minutes, and seeded onto the surface of each sample at a density of $5 \times 10^{5}$ cells/mL of final hydrogel solution, using $200 \mu \mathrm{L}$ of $\alpha$-MEM. The culture medium was replaced every day during the 3 days of cell culture.

For cell encapsulation assays, the gelatin and nanoparticles solution was thoroughly mixed with the cells to obtain a final concentration of $10^{6}$ cells $/ \mathrm{mL}$ of hydrogel final solution. The isotropic and anisotropic hydrogels were prepared as previously described by placing $100 \mu \mathrm{L}$ of solution in silicon squared molds for evaluation of cell morphology and cytoskeleton organization, or $30 \mu \mathrm{L}$ of solution into $\mu$-Slide Angiogenesis coverslips for live/dead assay. For live/dead assay, only the isotropic hydrogels were prepared. The cell encapsulated hydrogels were incubated at $37^{\circ} \mathrm{C}$ for 90 minutes. After the incubation, $\alpha$-MEM culture medium was added to each well, replacing it every day during the culture duration.

\section{Live/dead assay}

Cells viability within nanocomposite hydrogels was assessed using calcein AM (stains live cells) and propidium iodide (stains dead cells). After 1 and 3 days of culture, hydrogels with encapsulated hASCs were washed with PBS, and then incubated with calcein AM and PI for 30 minutes at $37^{\circ} \mathrm{C}$. Thereafter, the samples were washed with PBS to reduce background fluorescence and visualized using confocal microscopy (TCS SP8, Leica Microsystems, Germany). The viability was evaluated by counting live and dead cells from six representative images for each condition.

\section{Evaluation of cell alignment}

After 3 days, the hydrogels with seeded or encapsulated hASCs were fixed with formalin 10\% (v/v). Cell cytoskeleton was stained using 0.2\% (v/v) Triton X-100 in PBS containing PhalloidinTRITC and nuclei were stained using DAPI. Finally, the stained samples were observed under 
confocal microscopy and at least six representative images for each condition were taken. Alignment was evaluated using the directionality plugin from Image J. For that, the channel corresponding to the cell cytoskeleton from confocal images was used after automatic contrast enhancement to obtain the directionality histograms. Then, Origin software was used to fit the results to a Gaussian distribution which was used to calculate the full with half medium (FWHM) and the deviation from the nanoparticles alignment direction.

\section{Statistical analysis}

The statistical analysis was managed with GraphPad Prism software version 7.0 (GraphPad Sotware Inc, San Diego, CA, USA), using two-way Analysis of Variance (ANOVA) test and Bonferroni post-test for multiple comparisons, to study the influence of two categorical independent variables. The values were considered different for a level of significance of $p<0.05$. The number of samples is indicated in each quantitative assay performed.

\section{Results and Discussion}

\section{Characterization of the hybrid magnetic nanoparticles}

The functionality and performance of nanoparticle systems has been shown to be significantly dependent on their colloidal stability in suspension or their adequate dispersibility within polymer matrices in nanocomposites, being in general negatively affected by aggregation phenomena. ${ }^{29,30,34}$ Moreover, since the physical and chemical surface characteristics of the nanoparticles can affect their dispersion and fate in physiological environments, surface engineering strategies are commonly applied in nanoparticle systems development for biomedical applications. In the particular case of iron oxide based MNP, different surface modifications have been applied not 
only to improve their colloidal stability but also their biocompatibility. ${ }^{35}$ Among them, bioinspired polydopamine (PDA) coatings have become a versatile and facile route for surface functionalization of organic or inorganic materials. ${ }^{29,36-39}$ Moreover, PDA coating provides a highly convenient synthesis route for bioconjugation of different molecules under mild reactive conditions. Therefore, in this study we explored these bioinspired and multifunctional coating to tether amino derivatives of polyethyleneglycol (PEG) onto the surface of the nanoparticles. By conveying steric repulsions among nanoparticle, it is expected that these PEG brushes improve their colloidal dispersion stability in different physiological conditions, as previously demonstrated in other nanoparticle systems. ${ }^{30,31,40}$

AFM, STEM and TEM were used to characterize the morphology and dimensions of the synthesized nanoparticles (Fig. 2). AFM analysis show that CNC exhibit the typical rod-like shape morphology with average length (L) of $206 \pm 43 \mathrm{~nm}$ and height of $12.06 \pm 4.17 \mathrm{~nm}$. After the coprecipitation of MNP onto $\mathrm{CNC}$ templates, the resulting hybrid mCNC show MNP with width (w) of $6.6 \pm 1.5 \mathrm{~nm}$ (measured from TEM images) well attached and spread over the CNC surface (Fig. S2), as previously demonstrated in other similar mCNC. ${ }^{41}$ After PDA coating, it can be seen that some of the particles are composed by more than one single $\mathrm{mCNC}$ resulting from their slight lateral aggregation and coupling during the coating process but, in general, pda-mCNC remain well individualized nanoparticles with the PDA coatings well visible in the STEM images, morphology which is maintained after grafting the PEG chains on their surface in the TEM image of peg-mCNC (width of $18.9 \pm 4.4 \mathrm{~nm}$ ). 

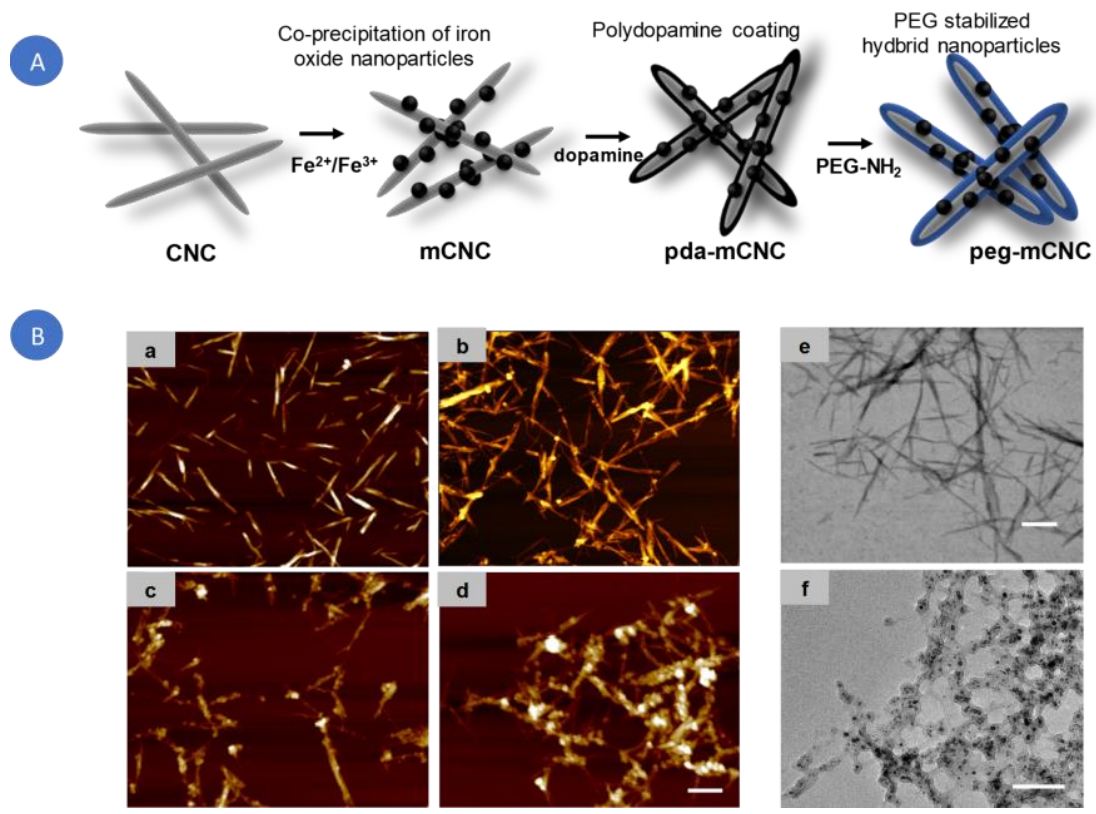

Fig. 2 Characterization of the developed nanoparticles. A) Schematic representation of the nanoparticles synthesis. B) AFM of a) $\mathrm{CNC}$, b) $\mathrm{mCNC}$, c) pda-mCNC and d) peg-mCNC; e) STEM of CNC; f) TEM of peg-mCNC. Scale bars $=200 \mathrm{~nm}$.

The chemical composition of the different nanoparticles was evaluated by FTIR spectroscopy, which confirmed the anchoring of MNP on the CNC, the PDA coating and the PEG grafting on their surface (Fig. S3). Furthermore, the crystallinity of CNC and the chemical identity of the MNP upon coating treatments with PDA and PEG was confirmed using XRD analysis (Fig. S3). The zeta potential of the synthesized nanoparticles was determined in order to evaluate the overall charge density, a parameter that has a major influence on the colloidal dispersion stability of nanoparticle systems (Table S1). As expected, CNC have a negatively charged surface with zeta potential of $-50 \mathrm{mV}$ due to their surface sulfate groups resulting from the sulfuric acid hydrolysis preparation method. ${ }^{42}$ By coupling MNP onto CNC surface and their further coating with PDA and PEG grafting, the surface charge of the final hybrid peg-mCNC decreases to $-34.1 \mathrm{mV}$, results that are in agreement with previous reports for PEG grafted PDA nanoparticles. ${ }^{31,36}$ 
The stability of the different nanoparticles in water and protein rich physiological solutions (here, we used human platelet lysate, PL) was evaluated by analysis of the particle size with DLS (Fig. S5). It should be noticed that, since the composite nanoparticles are not spherical, the measured hydrodynamic radius only provides an indication of the apparent size of the nanoparticles. However this method can be used to assess dispersion quality or state of aggregation of these non-spherical nanoparticles if the same equipment, sample preparation and protocol are employed ${ }^{43}$ The results of Fig. S5 show that, at all time points, peg-mCNC have smaller particle size in both solutions (water and PL). In theory, PEG grafting should lead to higher hydrodynamic nanoparticle sizes, suggesting therefore that the grafted PEG chains improved the colloidal dispersion and stability of peg-mCNC when compared to the other groups, as previously suggested in other nanoparticle systems, ${ }^{30,31}$ although it also tends to present some aggregation for longer incubation periods (around 60\% increase in hydrodynamic diameter after 24 hours in PL).

Altogether, these results suggest that our new peg-mCNC could significantly improve some of the most critical limitations assigned to hybrid $\mathrm{CNC} /$ magnetic nanoparticles as potential nanodevices or as active elements in biomaterials namely, their irreversible aggregation induced by the electrostatic interactions between sulphate ester groups and metal cations that screen the surface charges responsible for stabilizing the $\mathrm{CNC}$, thus changing the nanoscale nature of the final hybrid particles. ${ }^{44}$ In fact, in preliminary experiments, the production of the gelatin nanocomposite hydrogels proposed here was tested with $\mathrm{mCNC}$ or pda-mCNC. In both cases it was not possible to produce stable hydrogels due to extensive nanoparticle aggregation during the gelation period (see example in Fig. S6), highlighting the importance of the peg-mCNC shell composition to enable the development of the proposed nanocomposite hydrogel concept. 


\section{Morphological characterization of isotropic and anisotropic magnetic hydrogels}

The enzymatic reactions catalyzed by transglutaminases provide alternative methods to create injectable and covalently crosslinked gelatin hydrogels for various biomedical applications. ${ }^{45}$ Microbial transglutaminase (mTGase) in particular, which catalyzes an acyl transfer reaction that leads to the formation of crosslinked $\varepsilon$-( $\gamma$-glutamyl)-lysine isopeptide bonds between $\gamma$ carboxyamide groups of glutamyl residue and $\varepsilon$-amino groups of lysine residue, ${ }^{46}$ has the advantage of having a catalytic activity independent of calcium ions, differing in this way from transglutaminases of human or other mammalian animals origin. ${ }^{47}$ Previous studies have shown that mTGase can create stable covalently crosslinked gelatin hydrogels, ${ }^{47-49}$ and the resulting biomaterials are biocompatible, non-immunogenic and show low cytotoxicity while maintaining their injectability. ${ }^{50}$ Considering these properties, mTGase crosslinking was used to produce the injectable gelatin nanocomposite hydrogels as shown in Fig. 3. 


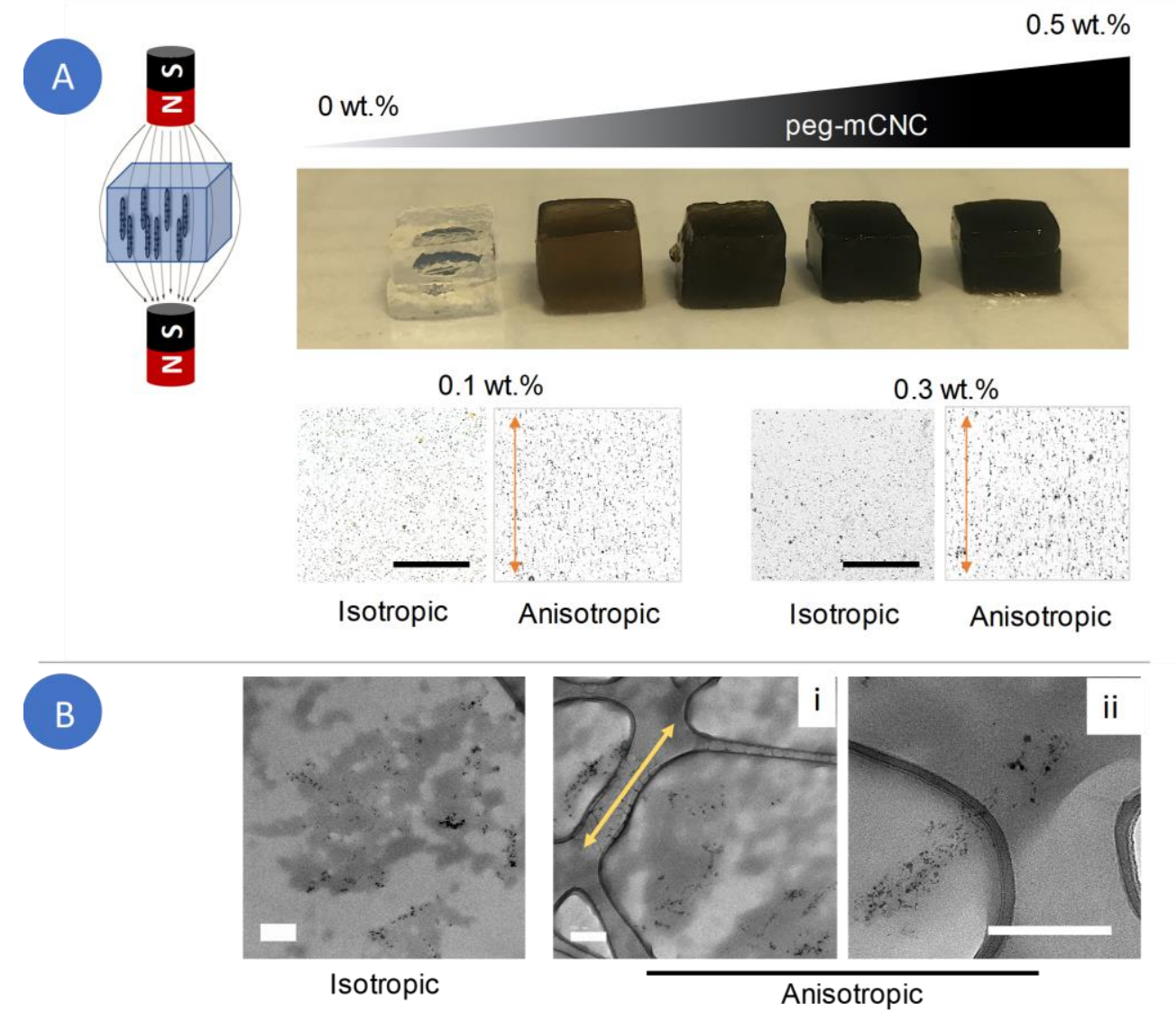

Fig. 3 Characterization of the nanoparticles alignment in the hydrogels. (A) Image of the developed nanocomposite hydrogels (from left to right: 0, 0.1, 0.2, 0.3 and 0.5 wt.\%) and optical microscopy images of aligned and non-aligned nanoparticles within 0.1 wt.\% and 0.3 wt.\% hydrogels (scale bar $=200 \mu \mathrm{m}$ ). (B) TEM images of $0.3 \mathrm{wt} . \%$ isotropic and anisotropic hydrogels i) low magnification and ii) high magnification (scale bar $=200 \mathrm{~nm}$ ). Arrows indicate the alignment direction.

In order to determine the magnetic field strength required to induce the hybrid peg-mCNC alignment, preliminary tests were performed using hydrogel formulations with different nanoparticles content (0.3 and 0.5 wt.\%) and magnetic fields varying between $108-400 \mathrm{mT}$. It was observed that the extent of nanoparticles alignment achieved at low magnetic fields (108 mT) 
is comparable with those obtained at higher magnetic fields (Fig. S7), irrespective of peg-mCNC concentration, being therefore the selected condition for subsequent studies. The alignment of peg$\mathrm{mCNC}$ within the 3D anisotropic hydrogels to the direction of the magnetic field was observed at microscopic level using optical microscopy (Fig. 3A). Furthermore, to demonstrate the nanoparticles alignment with the direction of the magnetic field at the nanoscale, ultrathin sections of isotropic and anisotropic hydrogels were imaged using TEM. As observed in Fig. 3B, nanoparticles in isotropic hydrogels show a random distribution while anisotropic hydrogels show ordered domains of nanoparticle aggregates.

The influence of peg-mCNC incorporation and exposure to uniform magnetic fields on the microstructure of hydrogels was investigated by SEM. Representative images of the analyzed cross-sections of isotropic and anisotropic freeze-dried hydrogels are depicted in Fig. 4. Upon to a low strength magnetic field $(108 \mathrm{mT})$, the hydrogels present well defined honeycomb-like anisotropic porous structures, whereas in the absence of magnetic field during crosslinking, hydrogels present random and disorganized microstructures. Moreover, although the increment of peg-mCNC concentration leads to some improvement in the definition of the anisotropic structures, peg-mCNC concentrations as low as $0.1 \mathrm{wt} . \%$, representing a volume fraction of MNP in the nanocomposite of only 0.0005 vol.\%, could already induce a considerable level of structural lamellae anisotropy. Remarkably, Fig. 4 shows that anisotropic hydrogels present pores with lower aspect ratio and data scattering compared with isotropic hydrogels, suggesting a higher shape regularity.

Micro-CT analysis was used to examine the presence of aligned domains along the 3D space of hydrated hydrogels (Fig. 4B), in order to confirm the SEM results obtained on freeze dried samples (Fig. 4B). Hydrogels with an intermediate peg-mCNC concentration of $0.3 \mathrm{wt} . \%$ were selected to 
perform this analysis. The reconstructed micro-CT images of anisotropic hydrogels confirm the presence of preferential 3D aligned domains, while random isotropic hydrogels show a nonpreferential distribution of pixel intensity, as confirmed by the directionality analysis (Fig. 4B), suggesting the presence of an ordered hydrogel microstructure.
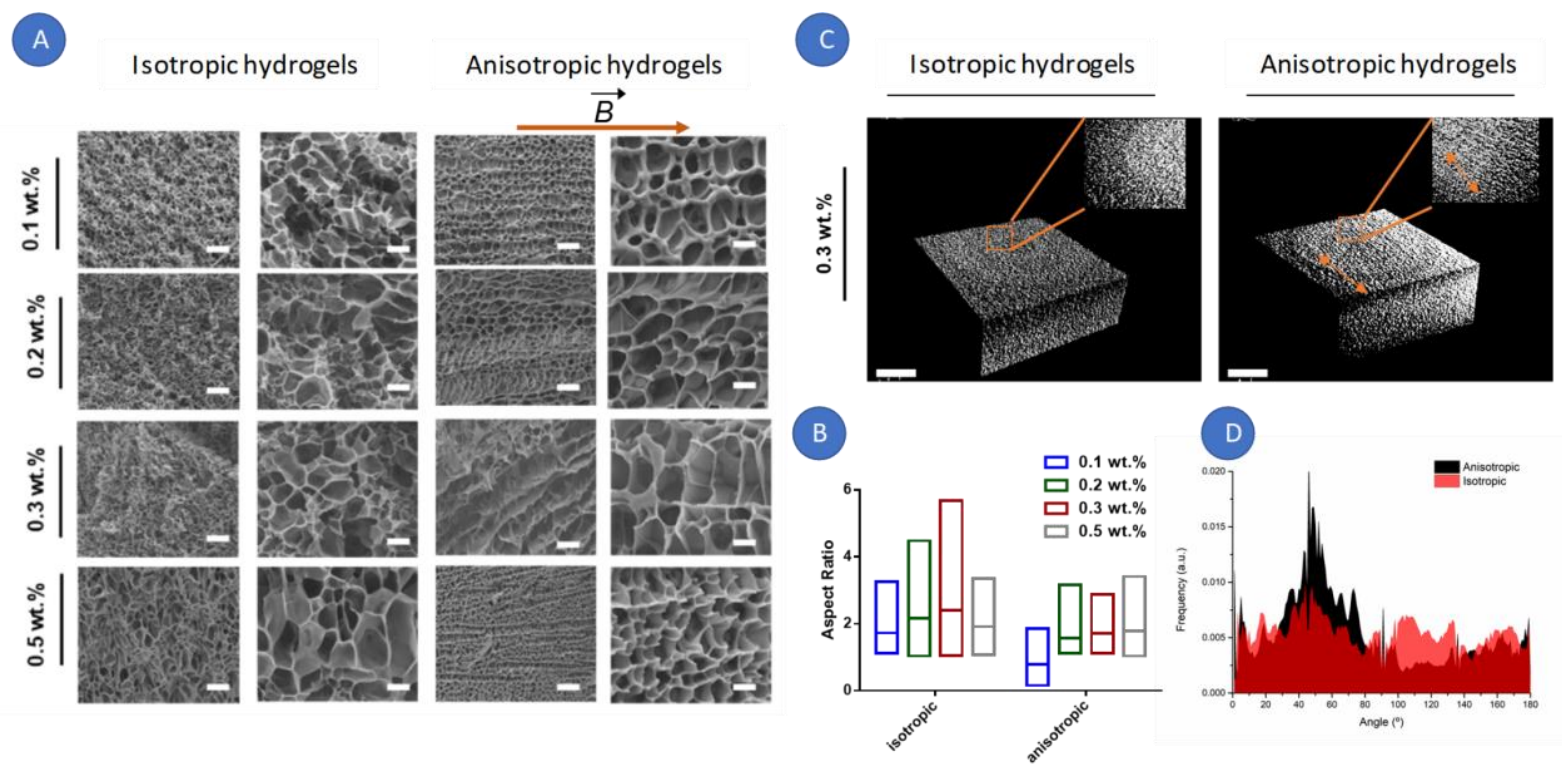

Fig. 4 Morphological characterization of nanocomposite hydrogels. A) SEM images of isotropic and anisotropic freeze-dried hydrogels with $0.1,0.2,0.3$ and $0.5 \mathrm{wt} . \%$ nanoparticles (scale bar $=$ $10 \mu \mathrm{m})$; B) Distribution of pore aspect ratio in freeze-dried isotropic and anisotropic hydrogels. C) Micro-CT images of isotropic and anisotropic hydrogels with $0.3 \mathrm{wt} . \%$ nanoparticles (scale bar $=$ $1 \mathrm{~mm}$ ); D) Directionality analysis of micro-CT reconstructed images. Arrows indicate the alignment direction.

These results support the validation of the proposed concept, where the combination of MNP with rod-like CNC synergistically contribute to introduce microstructural anisotropy within the 3D space of hydrogels at low nanoparticle concentration and applying low magnetic fields. 
Remarkably, these results can be easily attained with simple permanent magnets without requiring dedicated equipment (at 0.1-0.5 wt.\% of nanoparticles and magnetic field strength of $108 \mathrm{mT}$ ), representing an advantage when considering the implementation of this concept in clinical scenarios. For example, as comparison, a similar concept has been developed by inducing the magnetic alignment of diamagnetic $\mathrm{CNC}$ within injectable synthetic nanocomposite hydrogels. ${ }^{12}$ However, higher concentrations of $\mathrm{CNC}(0.2-1.65 \mathrm{wt} . \%)$ and magnetic fields $(0.56-1.2 \mathrm{~T})$ were used to produce hydrogels with physical anisotropic properties.

Interestingly, all our nanocomposite formulations show relatively low swelling behavior (between 5 and 20\%), in the same order as that of the control gelatin hydrogels (18.2\%). Although some statistically significant differences exist among the different formulations, no obvious trend can be inferred from this data (Fig. S8).

\section{Magnetic properties}

The magnetization curves of magnetic nanoparticles and nanocomposite hydrogels were measured at room temperature and are shown in Fig. 5. The low remanence on the magnetization loops confirm the superparamagnetic character of mCNC and peg-mCNC (Fig. 5A). mCNC show a magnetization of saturation $\left(\mathrm{M}_{\mathrm{s}}\right)$ of $18.2 \mathrm{emu} \mathrm{g}^{-1}$, which is reduced to $6.7 \mathrm{emu} \mathrm{g}^{-1}$ after the PDA coating and PEG grafting, as result of their proportionally lower magnetic material content. The

values obtained are in line with other reports on the synthesis of mCNC $\left.\left(\approx 20 \mathrm{emu} \mathrm{g}^{-1}\right)\right)^{28,51}$ Regarding $\mathrm{M}_{\mathrm{s}}$ values of the developed hydrogels, they are proportional to the amount of MNP present on the sample (Fig. 5B) and vary between $0.09 \mathrm{emu} \mathrm{g}^{-1}$ (0.1 wt.\%, black line) and 0.41 emu $\mathrm{g}^{-1}\left(0.3 \mathrm{wt} . \%\right.$ hydrogels, green line). Although this $\mathrm{M}_{\mathrm{s}}$ range might seem apparently low, it is in the same order of other magnetic biomaterials that have shown the ability to promote cell proliferation and/or differentiation triggered by stimulation with external magnetic fields as low 
as 2 to $10 \mathrm{mT} .{ }^{52-54}$ Therefore, although not evaluated under the scope of this study, it is plausible to hypothesize that our multifunctional nanocomposite hydrogels might be combined with remote magnetic stimulation strategies to promote or induce specific cell behaviors in cellular or acellular TERM approaches.
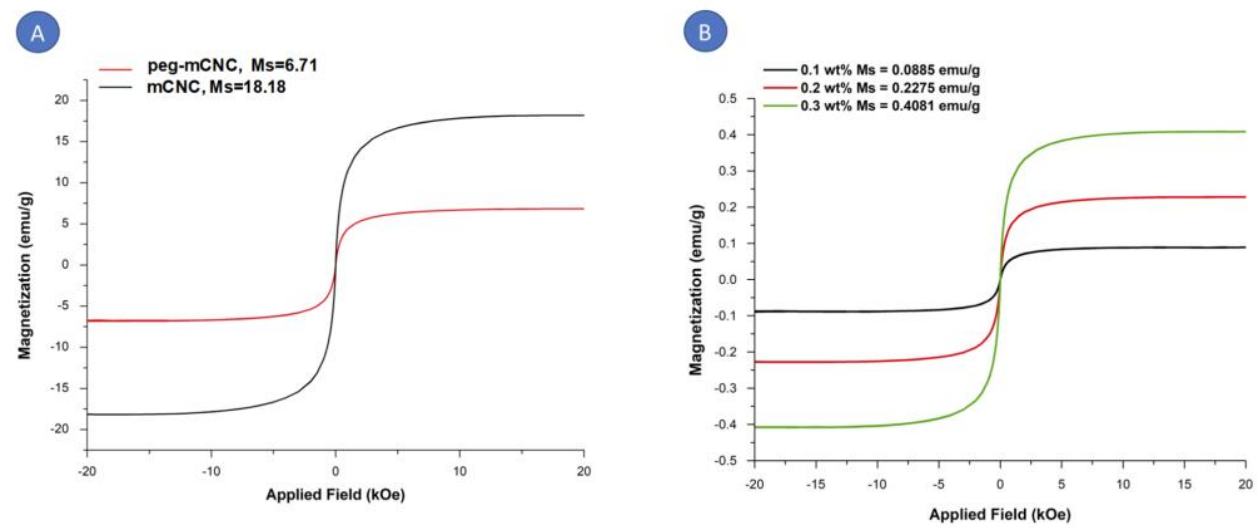

Fig. 5 Magnetic hysteresis curves normalized to the amount of the initial samples: A) mCNC; pegmCNC; B) developed hydrogels formulations (0.1 wt.\% - black line; 0.2 wt.\% - red line; 0.3 wt.\% - green line).

\section{Mechanical properties of developed nanocomposite hydrogels}

Previous studies have shown that the reinforcement of the hydrogel matrices with the incorporation of nanoparticles as $\mathrm{CNC}$ or MNP had a significant impact on their mechanical properties. $^{17,22,55}$ The effect of the nanoparticles content on the hydrogels gelation kinetics and bulk mechanical properties of (isotropic) hydrogels were assessed by rheology analysis (Fig. 6). The impact of peg-mCNC addition in the hydrogels gelation kinetics is depicted in Fig. 6A, demonstrating that their influence on the hydrogels gelling point is not significant and is comprised between $895 \pm 10 \mathrm{~s}(0.5 \mathrm{wt} . \%$ peg-mCNC) and $950 \pm 20 \mathrm{~s}(0 \mathrm{wt} . \%$ peg-mCNC), which is in the range of other injectable hydrogels based on natural polymers for tissue engineering applications. ${ }^{56}$ 
Regarding the hydrogels bulk viscoelastic properties (Fig. 6B), results show a positive dependence of the shear elastic modulus (G') on the concentration of nanoparticles. Hydrogels G' (at the linear viscoelastic region) gradually increase from $796 \pm 94 \mathrm{~Pa}$ without nanoparticles up to $2280 \pm 466 \mathrm{~Pa}$ at the highest nanoparticles content $(0.5 \mathrm{wt} . \%)$. These results show that the incorporation of pegmCNC in the gelatin matrix leads to up to 3 -fold stiffer hydrogels, resulting from their good dispersion in the polymer matrix and their function not only as physical reinforcement elements but also as effective matrix crosslinking elements enabled by the PDA coating (trough Schiff base and Michaels addition reactions with amine groups of gelatin, Fig. 1).

To evaluate hydrogels mechanical properties anisotropy, DMA analysis in compression mode and under simulated physiological conditions was used (Fig. 6C). Hydrogels with nanoparticles alignment parallel to the applied compressive force showed significantly higher storage modulus values (E') than the hydrogels with perpendicular nanoparticles alignment, further supporting the anisotropy of the hydrogels microstructure induced by the nanoparticles alignment.

A

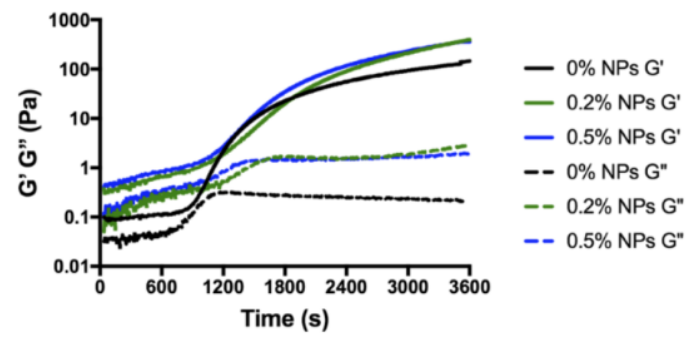

C
B

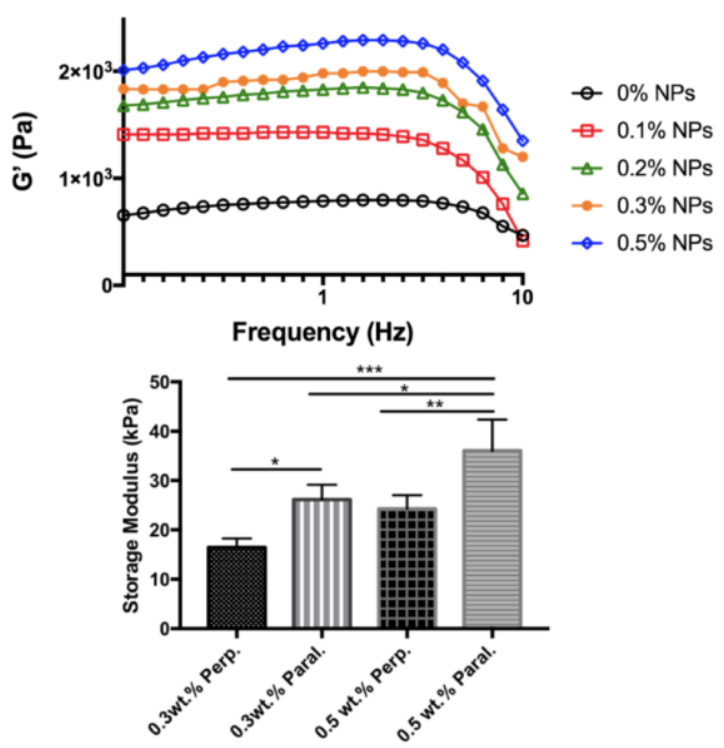


Fig. 6 Mechanical characterization of the developed hydrogels. A) Representative time-sweep curves of isotropic hydrogels; B) Elastic modulus (G') from rheological analysis of isotropic hydrogels; C) Storage modulus $E^{\prime}(\mathrm{kPa})-$ of 0.3 and 0.5 wt.\% anisotropic hydrogels with perpendicularly and parallely aligned nanoparticles from DMA analysis. One symbol $p<0.05$, two symbols $\mathrm{p}<0.01$, three symbols $\mathrm{p}<0.001$ by Two - Way Anova followed by Bonferroni post test multiple comparisons.

\section{Biological performance}

The ability of hydrogels to support cell viability was evaluated by live/dead assay using encapsulated hASCs after 1 and 3 days of culture. Confocal images allowed to conclude that all the formulations $(0,0.1,0.2,0.3$ and $0.5 \mathrm{wt} . \%)$ show high rates of cell viability at both time points, demonstrating that the nanocomposite biomaterials developed in this work are not cytotoxic (Fig. 7). Nevertheless, the hydrogels with the highest content of nanoparticles presented the lowest number of live cells $(\sim 78 \%$ ), potentially indicating that higher peg-mCNC loadings ( $>0.5 \mathrm{wt} . \%$ ) may have a negative influence on cell viability. 

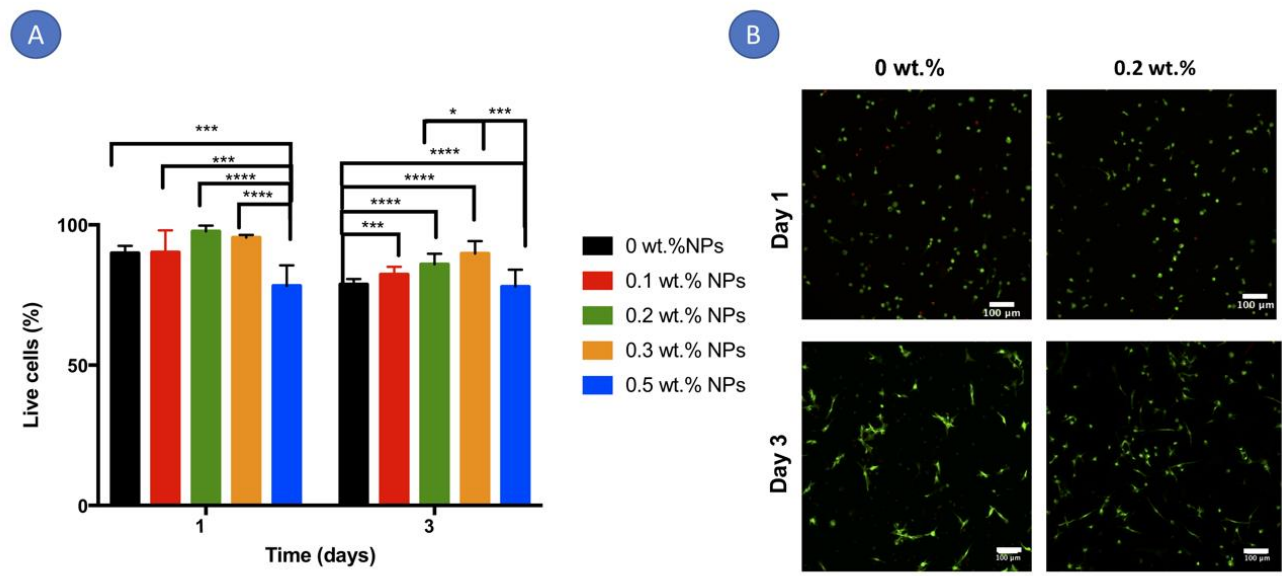

0.5 wt.\%

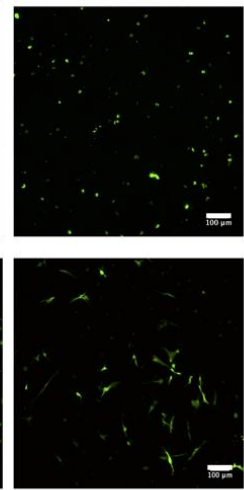

Fig. 7 Cell viability of hASCs encapsulated in hydrogels containing different amounts of pegmCNC nanoparticles $(0,0.1,0.2,0.2$ and 0.5 wt.\%) after 1 and 3 days. A) Graphical representation of the number of cells stained live in relation to the total number of cells ( $\mathrm{n}=6)$; B) Representative images of cells in the hydrogels after live/dead staining (green - live and red - dead). One symbol $\mathrm{p}<0.05$, two symbols $\mathrm{p}<0.01$, three symbols $\mathrm{p}<0.001$, four symbols $\mathrm{p}<0.0001$ by Two - Way Anova followed by Bonferroni post test multiple comparisons.

The effect of hydrogel alignment on cell morphology and cytoskeleton organization was studied through both 2D (cell seeding) and 3D (cell encapsulation) experiments. As hydrogels with low peg-mCNC loadings $(0.1,0.2$ and 0.3 wt.\%) exhibit anisotropic microstructures and high cell viability, they were selected for these assays. For the 2D experiments, hASCs were seeded on the top of isotropic and anisotropic hydrogels and cell orientation on its surface was observed by confocal microscopy. After 1 day of cell culture, cells seeded on the nanocomposite hydrogels start to show the typical spindle shape although they do not present preferential orientation for the direction of the magnetic field, as shown by quantitative directionality analysis (Fig. S9). After 3 days of culture, cells seeded on 0.1 and $0.2 \mathrm{wt} . \%$ anisotropic hydrogels showed a directional 
growth aligned with the orientation of the nanoparticles, while cells on $0.3 \mathrm{wt} . \%$ anisotropic hydrogels showed a more random orientation (Fig. 8A). These findings are supported by the quantification of the cell cytoskeleton alignment (Fig. 8B). The unimodal narrow distribution of directions observed on 0.1 and $0.2 \mathrm{wt} . \%$ anisotropic hydrogels $\left(\mathrm{FWHM}=39.8 \pm 8.2^{\circ}\right.$ for $0.1 \mathrm{wt} . \%$ and $52.8 \pm 2.0^{\circ}$ for 0.2 wt. $\%$ hydrogels) was significantly different to the multimodal or flat distribution observed on the isotropic hydrogels $\left(\mathrm{FWHM}=104.0 \pm 62.4^{\circ}\right.$ for $0.1 \mathrm{wt} . \%$ and $129.0 \pm 62.5^{\circ}$ for 0.2 wt. $\%$ hydrogels). Even though a small increase in the FWHM was observed from 0.1 to 0.2 wt.\% hydrogels, this difference was not statistically significant (Fig. 8B). Moreover, the cytoskeleton alignment deviation from the nanoparticles orientation observed on the anisotropic hydrogels $\left(15.8 \pm 2.5^{\circ}\right.$ for $\left.0.1 \mathrm{wt} . \%\right)$ was lower than on our isotropic hydrogels (54.1 $\pm 30.6^{\circ}$ for $\left.0.1 \mathrm{wt} . \%\right)$ and comparable to that of anisotropic hydrogels containing magnetically aligned CNC (1.65 wt.\% nanoparticles content aligned with $560 \mathrm{mT}) .{ }^{12}$ On the other hand, cells seeded on $0.3 \mathrm{wt} . \%$ anisotropic hydrogels do not show a similar narrow distribution of directions $\left(\mathrm{FWHM}=89.1 \pm 61.5^{\circ}\right)$ and present a higher cytoskeleton alignment deviation and dispersion from the nanoparticles orientation $\left(27.8 \pm 18.2^{\circ}\right)$. The capacity of the anisotropic hydrogels to induce cell alignment in 3D was tested by encapsulation of hASCs. The cells encapsulated in the isotropic and anisotropic hydrogels were able to spread within the hydrogel and exhibited spindle-shaped morphology after 3 days of culture (Fig. 8C and Fig. S9). Furthermore, image analysis shows preferential orientation for cells encapsulated within anisotropic hydrogels whereas in isotropic hydrogels cells have a more random distribution, which was particularly visible in $0.2 \mathrm{wt} . \%$ hydrogels as confirmed by quantitative directionality analysis (Fig. 8D). In order to investigate cell alignment at single cell level, high magnification confocal images with bright field overlaying were acquired (Fig. 8D and Fig. S10). Cells present highly organized actin filaments aligned to the 
visible nanoparticles strings orientation in 3D. Although the study of this mechanism was beyond the scope of this work, we hypothesize that the nanotopographical cues provided by the stiff nanoparticles within the soft gelatin matrix may enhance cell-substrate adhesion and actin extension and contraction, promoting cell spreading in one direction, as observed in previous works. ${ }^{57,58}$ However, this effect is lost when 0.3 wt.\% nanoparticles are used, suggesting the importance of concrete dimensions and/or spacing between magnetically aligned nanoparticles to achieve cell alignment. This represents a limitation of the present study and the influence of these parameters on cell alignment should be further evaluated in future studies. 


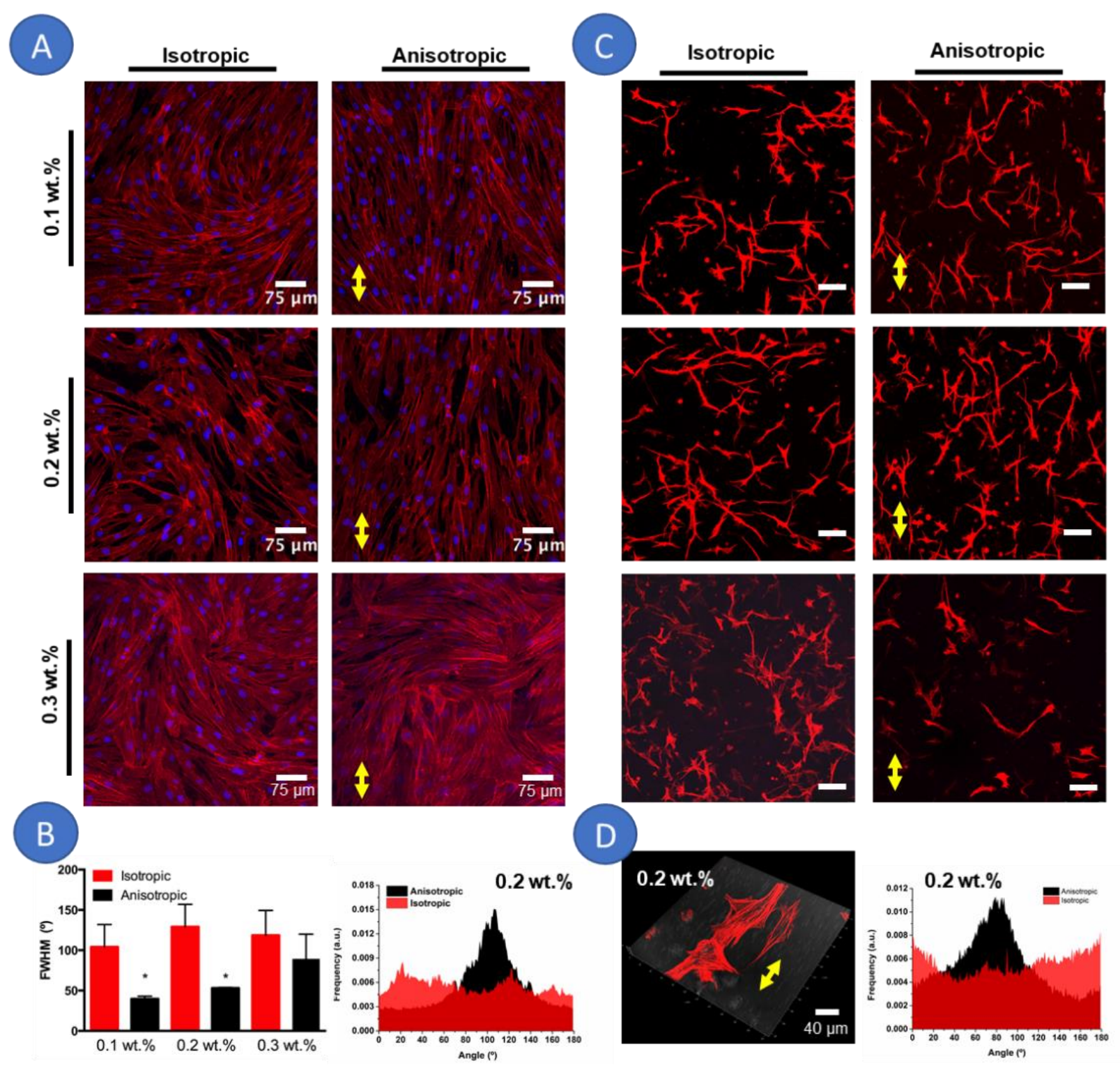

Fig. 8 Effect of isotropic and anisotropic hydrogels on cell alignment. Representative images of hASCs (A) seeded or (C) encapsulated in the hydrogels after 3 days of culture (red - cytoskeleton and blue - nucleus). Representative directionality histograms of cytoskeleton organization of cells (B) seeded and (D) encapsulated cells onto $0.2 \mathrm{wt} \% \%$ hydrogels, respectively. A multimodal or flat distribution denotes isotropic organization whereas a unimodal distribution indicates alignment. The full with half medium (FWHM) of the distribution was calculated for cells seeded on 
hydrogels. One symbol $\mathrm{p}<0.05$, by Two - Way Anova followed by Bonferroni post test multiple comparisons. (D) High magnification image of the peg-mCNC/cell co-alignment: Cell cytoskeleton (red color) is aligned with the peg-mCNC orientation (bright field). The yellow arrow indicates the orientation of the nanoparticles in the anisotropic hydrogels. In (C) scale bar $=100$ $\mu \mathrm{m}$.

It is worth noting that some literature suggests that cells can self-align using high strength magnetic fields $(>10 \mathrm{~T})$ or under continuous exposure to magnetic fields of lower magnitude but over multiple days. ${ }^{59-61}$ In the present study, such effects of low strength magnetic fields on cells orientation might be negligible since they were only seeded after crosslinking of the hydrogels, or in the case of encapsulated cells, they were only under the influence of the low magnetic field during a short crosslinking time. Actually, after 1 day of culture, cells seeded or encapsulated in the nanocomposite hydrogels, do not show preferential orientation for the direction of the magnetic field (Fig. S8). Therefore, the increase in cell alignment observed in the anisotropic hydrogels can be mainly attributed to the anisotropic microstructure within the gel and not to the interaction of the magnetic field with the cells.

The ability of the anisotropic hydrogels created in this study to readily align cells either on the surface or encapsulated within 3D matrices, suggests the potential of these system as a platform to develop structured materials for functional tissue engineering applications, including biomimicry of highly anisotropic tissues such as tendons. 


\section{Conclusions}

In this work, we demonstrated that with low concentrations of peg-mCNC (0.1-0.5 wt.\%) and uniform magnetic fields with strengths as low as $108 \mathrm{mT}$, it is possible to obtain nanoparticles alignment within nanocomposite hydrogels, which result in biomaterials with anisotropic microstructure and remarkable mechanical properties. The biological performance of selected nanocomposite hydrogels formulations was studied using human adipose tissue derived stem cells. Cells encapsulated in nanocomposite hydrogels showed high rates of viability demonstrating that the nanocomposite biomaterials are not cytotoxic. Remarkably, the microstructural patterns stemming from nanoparticles alignment induced the directional growth of seeded and encapsulated cells in the hydrogels. Overall, these results suggest that the proposed concept might find interesting applications as minimal invasive tissue engineering and regenerative medicine strategies for anisotropic tissues.

\section{Supporting Information}

Details of the materials and methods of dynamic light scattering analysis (DLS), thermogravimetric analysis (TGA), fourier transform infrared spectroscopy (FTIR) and X-ray diffraction analysis (XRD); Chemical characterization, preliminary optimization of nanoparticles alignment; Magnetic system used to align nanoparticles and develop anisotropic hydrogels. Supplementary results: zeta potential of the different developed nanoparticles; TGA of CNC and peg-mCNC; DLS results; Microscopic images of nanoparticles within isotropic and anisotropic hydrogels for different magnetic field strength; Swelling behavior of the hydrogels; Cell culture experiments at day 1; High magnification image of the peg-mCNC/cell co-alignment. 


\section{AUTHOR INFORMATION}

\section{Author Contributions}

The manuscript was written through contributions of all authors. All authors have given approval to the final version of the manuscript.

\section{Acknowledgment}

Authors acknowledge Fundação para a Ciência e a Tecnologia for SFRH/BPD/112459/2015 (RD), EU’s H2020 programme for Marie Skłodowska-Curie grant agreement 706996 and for European Research Council grant agreement 772817 - MagTendon, project RECOGNIZE (UTAPICDT/CTM-BIO/0023/2014), project FOOD4CELLS (PTDC/CTM-BIO/4706/2014 - POCI-010145-FEDER 016716) (PB), and project NORTE-01-0145-FEDER-000021. The authors also acknowledge Dr. Paulo Freitas and Dr. Elvira Paz from INL (International Iberian Nanotechnology Laboratory) for VSM analysis. This work was carried out in part through the use of the INL Advanced Electron Microscopy, Imaging and Spectroscopy Facility. Dr Oliver Schraidt is acknowledged for the acquisition of TEM images.

\section{Notes}

The authors declare that there are no conflicts of interest.

\section{REFERENCES}

1. Sano, K.; Ishida, Y.; Aida, T. Synthesis of Anisotropic Hydrogels and Their Applications. Angew. Chemie Int. Ed. 2018, 57 (10), 2532-2543. https://doi.org/10.1002/anie.201708196. 
2. Snedeker, J. G.; Foolen, J. Tendon Injury and Repair - A Perspective on the Basic Mechanisms of Tendon Disease and Future Clinical Therapy. Acta Biomater. 2017, 63, 18 36. https://doi.org/10.1016/j.actbio.2017.08.032.

3. Kim, H. N.; Jiao, A.; Hwang, N. S.; Kim, M. S.; Kang, D. H.; Kim, D. H.; Suh, K. Y. Nanotopography-Guided Tissue Engineering and Regenerative Medicine. Adv. Drug Deliv. Rev. 2013, 65 (4), 536-558. https://doi.org/10.1016/j.addr.2012.07.014.

4. Keene, D. R.; Engvall, E.; Glanville, R. W. Ultrastructure of Type VI Collagen in Human Skin and Cartilage Suggests an Anchoring Function for This Filamentous Network. J. Cell Biol. 1988, 107 (5), 1995-2006. https://doi.org/10.1083/jcb.107.5.1995.

5. Naseri, N.; Deepa, B.; Mathew, A. P.; Oksman, K.; Girandon, L. Nanocellulose-Based Interpenetrating Polymer Network (IPN) Hydrogels for Cartilage Applications. $\begin{array}{lllll}\text { Biomacromolecules } & \text { 2016, } & 17 & \text { (11), }\end{array}$ https://doi.org/10.1021/acs.biomac.6b01243.

6. Memic, A.; Alhadrami, H. A.; Hussain, M. A.; Aldhahri, M.; Al Nowaiser, F.; Al-Hazmi, F.; Oklu, R.; Khademhosseini, A. Hydrogels 2.0: Improved Properties with Nanomaterial Composites for Biomedical Applications. Biomed. Mater. 2015, 11 (1), 014104. https://doi.org/10.1088/1748-6041/11/1/014104.

7. Song, F.; Li, X.; Wang, Q.; Liao, L.; Zhang, C. Nanocomposite Hydrogels and Their Applications in Drug Delivery and Tissue Engineering. J. Biomed. Nanotechnol. 2015, 11 (1), 40-52. https://doi.org/10.1166/jbn.2015.1962.

8. Mehrali, M.; Thakur, A.; Pennisi, C. P.; Talebian, S.; Arpanaei, A.; Nikkhah, M.; 
Dolatshahi-Pirouz, A. Nanoreinforced Hydrogels for Tissue Engineering: Biomaterials That Are Compatible with Load-Bearing and Electroactive Tissues. Adv. Mater. 2017, 29 (8), 1603612. https://doi.org/10.1002/adma.201603612.

9. Takemoto, Y.; Yamamoto, T.; Ikuma, N.; Uchida, Y.; Suzuki, K.; Shimono, S.; Takahashi, H.; Sato, N.; Oba, Y.; Inoue, R.; et al. Preparation, Characterization and Magnetic Behavior of a Spin-Labelled Physical Hydrogel Containing a Chiral Cyclic Nitroxide Radical Unit Fixed inside the Gelator Molecule. Soft Matter 2015, 11 (27), 5563-5570. https://doi.org/10.1039/C5SM01216C.

10. Zhao, Z.; Fang, R.; Rong, Q.; Liu, M. Bioinspired Nanocomposite Hydrogels with Highly Ordered Structures. Adv. Mater. 2017, $29 \quad$ (45), $\quad 1-16$. https://doi.org/10.1002/adma.201703045.

11. Erb, R. M.; Libanori, R.; Rothfuchs, N.; Studart, A. R. Composites Reinforced in Three Dimensions by Using Low Magnetic Fields. Science (80-. ). 2012, 335 (6065), 199-204. https://doi.org/DOI 10.1126/science.1210822.

12. De France, K. J.; Yager, K. G.; Chan, K. J. W.; Corbett, B.; Cranston, E. D.; Hoare, T. Injectable Anisotropic Nanocomposite Hydrogels Direct in Situ Growth and Alignment of $\begin{array}{llllll}\text { Myotubes. } & \text { Nano } & \text { Lett. } & \text { 2017, } & 17 & \text { (10), }\end{array}$ https://doi.org/10.1021/acs.nanolett.7b03600.

13. Xu, F.; Inci, F.; Mullick, O.; Gurkan, U. A.; Sung, Y.; Kavaz, D.; Li, B.; Denkbas, E. B.; Demirci, U. Release of Magnetic Nanoparticles from Cell-Encapsulating Biodegradable Nanobiomaterials. ACS Nano 2012, 6 (8), 6640-6649. https://doi.org/10.1021/nn300902w. 
14. Qin, J.; Asempah, I.; Laurent, S.; Fornara, A.; Muller, R. N.; Muhammed, M. Injectable Superparamagnetic Ferrogels for Controlled Release of Hydrophobic Drugs. Adv. Mater. 2009, 21 (13), 1354-1357. https://doi.org/10.1002/adma.200800764.

15. Zhang, Y.; Yang, B.; Zhang, X.; Xu, L.; Tao, L.; Li, S.; Wei, Y. A Magnetic Self-Healing Hydrogel. Chem. Commun. 2012, 48 (74), 9305. https://doi.org/10.1039/c2cc34745h.

16. Li, Y.; Huang, G.; Zhang, X.; Li, B.; Chen, Y.; Lu, T.; Lu, T. J.; Xu, F. Magnetic Hydrogels and Their Potential Biomedical Applications. Adv. Funct. Mater. 2013, 23 (6), 660-672. https://doi.org/10.1002/adfm.201201708.

17. Ramón-Azcón, J.; Ahadian, S.; Estili, M.; Liang, X.; Ostrovidov, S.; Kaji, H.; Shiku, H.; Ramalingam, M.; Nakajima, K.; Sakka, Y.; et al. Dielectrophoretically Aligned Carbon Nanotubes to Control Electrical and Mechanical Properties of Hydrogels to Fabricate Contractile Muscle Myofibers. Adv. Mater. 2013, 25 (29), 4028-4034. https://doi.org/10.1002/adma.201301300.

18. Rose, J. C.; Gehlen, D. B.; Haraszti, T.; Köhler, J.; Licht, C. J.; De Laporte, L. Biofunctionalized Aligned Microgels Provide 3D Cell Guidance to Mimic Complex Tissue $\begin{array}{lllll}\text { Matrices. } & \text { Biomaterials } & \mathbf{2 0 1 8}, & 163, & 128-141 .\end{array}$ https://doi.org/10.1016/j.biomaterials.2018.02.001.

19. Rose, J. C.; Rahimi, K.; Ko, J.; Mo, M.; Laporte, L. De. Nerve Cells Decide to Orient inside an Injectable Hydrogel with Minimal Structural Guidance. Nano Lett. 2017, 17, 3782-3791. https://doi.org/10.1021/acs.nanolett.7b01123.

20. Hu, K.; Sun, J.; Guo, Z.; Wang, P.; Chen, Q.; Ma, M.; Gu, N. A Novel Magnetic Hydrogel 
with Aligned Magnetic Colloidal Assemblies Showing Controllable Enhancement of Magnetothermal Effect in the Presence of Alternating Magnetic Field. Adv. Mater. 2015, 27 (15), 2507-2514. https://doi.org/10.1002/adma.201405757.

21. Antman-Passig, M.; Shefi, O. Remote Magnetic Orientation of 3D Collagen Hydrogels for Directed Neuronal Regeneration. Nano Lett. 2016, 16 (4), 2567-2573. https://doi.org/10.1021/acs.nanolett.6b00131.

22. Domingues, R. M. A.; Silva, M.; Gershovich, P.; Betta, S.; Babo, P.; Caridade, S. G.; Mano, J. F.; Motta, A.; Reis, R. L.; Gomes, M. E. Development of Injectable Hyaluronic Acid/Cellulose Nanocrystals Bionanocomposite Hydrogels for Tissue Engineering Applications. Bioconjug. Chem. 2015, $26 \quad$ (8), 1571-1581. https://doi.org/10.1021/acs.bioconjchem.5b00209.

23. Domingues, R. M. A.; Chiera, S.; Gershovich, P.; Motta, A.; Reis, R. L.; Gomes, M. E. Enhancing the Biomechanical Performance of Anisotropic Nanofibrous Scaffolds in Tendon Tissue Engineering: Reinforcement with Cellulose Nanocrystals. Adv. Healthc. Mater. 2016, 5 (11), 1364-1375. https://doi.org/10.1002/adhm.201501048.

24. Laranjeira, M.; Domingues, R. M. A.; Costa-Almeida, R.; Reis, R. L.; Gomes, M. E. 3D Mimicry of Native-Tissue-Fiber Architecture Guides Tendon-Derived Cells and Adipose Stem Cells into Artificial Tendon Constructs. Small 2017, 13 (31), 1700689. https://doi.org/10.1002/smll.201700689.

25. Domingues, R. M. A.; Gomes, M. E.; Reis, R. L. The Potential of Cellulose Nanocrystals in Tissue Engineering Strategies. Biomacromolecules 2014, 15 (7), 2327-2346. https://doi.org/10.1021/bm500524s. 
26. Bondeson, D.; Mathew, A.; Oksman, K. Optimization of the Isolation of Nanocrystals from Microcrystalline Cellulose by Acid Hydrolysis. Cellulose 2006, 13 (2), 171-180. https://doi.org/10.1007/s10570-006-9061-4.

27. Dhar, P.; Kumar, A.; Katiyr, V. Magnetic Cellulose Nanocrystals-Based Anisotropic Polylactic Acid Nanocomposite Films : Influence on Electrical, Magnetic, Thermal and Mechanical Properties. ACS Appl. Mater. Interfaces 2016, 8, 18393-18409. https://doi.org/10.1021/acsami.6b02828.

28. Nypelö, T.; Rodriguez-Abreu, C.; Rivas, J.; Dickey, M. D.; Rojas, O. J. MagnetoResponsive Hybrid Materials Based on Cellulose Nanocrystals. Cellulose 2014, 21 (4), 2557-2566. https://doi.org/10.1007/s10570-014-0307-2.

29. Shi, Z.; Tang, J.; Chen, L.; Yan, C.; Tanvir, S.; Anderson, W. A.; Berry, R. M.; Tam, K. C. Enhanced Colloidal Stability and Antibacterial Performance of Silver Nanoparticles/Cellulose Nanocrystal Hybrids. J. Mater. Chem. B 2015, 3 (4), 603-611. https://doi.org/10.1039/C4TB01647E.

30. Liu, J.; Xu, H.; Tang, X.; Xu, J.; Jin, Z.; Li, H.; Wang, S.; Gou, J.; Jin, X. Simple and Tunable Surface Coatings via Polydopamine for Modulating Pharmacokinetics, Cell Uptake and Biodistribution of Polymeric Nanoparticles. RSC Adv. 2017, 7 (26), 15864-15876. https://doi.org/10.1039/C7RA01354J.

31. Zhong, X.; Yang, K.; Dong, Z.; Yi, X.; Wang, Y.; Ge, C.; Zhao, Y.; Liu, Z. Polydopamine as a Biocompatible Multifunctional Nanocarrier for Combined Radioisotope Therapy and Chemotherapy of Cancer. Adv. Funct. Mater. 2015, 25 (47), 7327-7336. https://doi.org/10.1002/adfm.201503587. 
32. Rada, T.; Reis, R. L.; Gomes, M. E. Distinct Stem Cells Subpopulations Isolated from Human Adipose Tissue Exhibit Different Chondrogenic and Osteogenic Differentiation Potential. Stem Cell Rev. Reports 2011, 7 (1), 64-76. https://doi.org/10.1007/s12015-010$9147-0$.

33. Carvalho, A. F.; Gasperini, L.; Ribeiro, R. S.; Marques, A. P.; Reis, R. 1. Control of Osmotic Pressure to Improve Cell Viability in Cell-Laden Tissue Engineering Constructs. J. Tissue Eng. Regen. Med. 2018, 12 (2), e1063-e1067. https://doi.org/10.1002/term.2432.

34. Yang, D.; Huang, S.; Wu, Y.; Ruan, M.; Li, S.; Shang, Y.; Cui, X.; Wang, Y.; Guo, W. Enhanced Actuated Strain of Titanium Dioxide/Nitrile-Butadiene Rubber Composite by the Biomimetic Method. RSC Adv. 2015, $5 \quad$ (80), $\quad 65385-65394$. https://doi.org/10.1039/C5RA12311A.

35. Mout, R.; Moyano, D. F.; Rana, S.; Rotello, V. M. Surface Functionalization of Nanoparticles for Nanomedicine. Chem. Soc. Rev. 2012, 41 (7), 2539. https://doi.org/10.1039/c2cs15294k.

36. Liu, Y.; Ai, K.; Lu, L. Polydopamine and Its Derivative Materials : Synthesis and Promising Applications in Energy, Environmental, and Biomedical Fields. 2014.

37. Zhou, S.; Chang, Q.; Lu, F.; Xing, M. Injectable Mussel-Inspired Immobilization of Platelet-Rich Plasma on Microspheres Bridging Adipose Micro-Tissues to Improve Autologous Fat Transplantation by Controlling Release of PDGF and VEGF, Angiogenesis, Stem Cell Migration. Adv. Healthc. Mater. 2017, 6 (22), 1700131. https://doi.org/10.1002/adhm.201700131. 
38. Martín, M.; Salazar, P.; Villalonga, R.; Campuzano, S.; Pingarrón, J. M.; González-Mora, J. L. Preparation of Core-Shell Fe3O4@poly(Dopamine) Magnetic Nanoparticles for Biosensor Construction. J. Mater. Chem. B 2014, 2 (6), 739-746. https://doi.org/10.1039/C3TB21171A.

39. Mazur, M.; Barras, A.; Kuncser, V.; Galatanu, A.; Zaitzev, V.; Turcheniuk, K. V.; Woisel, P.; Lyskawa, J.; Laure, W.; Siriwardena, A.; et al. Iron Oxide Magnetic Nanoparticles with Versatile Surface Functions Based on Dopamine Anchors. Nanoscale 2013, 5 (7), 2692. https://doi.org/10.1039/c3nr33506b.

40. Park, J.; Kadasala, N. R.; Abouelmagd, S. A.; Castanares, M. A.; Collins, D. S.; Wei, A.; Yeo, Y. Polymer-Iron Oxide Composite Nanoparticles for EPR-Independent Drug Delivery. $\quad$ Biomaterials 2016, 285-295. https://doi.org/10.1016/j.biomaterials.2016.06.007.

41. Mahmoud, K. A.; Lam, E.; Hrapovic, S.; Luong, J. H. T. Preparation of Well-Dispersed Gold/Magnetite Nanoparticles Embedded on Cellulose Nanocrystals for Efficient Immobilization of Papain Enzyme. ACS Appl. Mater. Interfaces 2013, 5 (11), 4978-4985. https://doi.org/10.1021/am4007534.

42. Boluk, Y.; Lahiji, R.; Zhao, L.; McDermott, M. T. Suspension Viscosities and Shape Parameter of Cellulose Nanocrystals (CNC). Colloids Surfaces A Physicochem. Eng. Asp. 2011, 377 (1-3), 297-303. https://doi.org/10.1016/j.colsurfa.2011.01.003.

43. Foster, E. J.; Moon, R. J.; Heux, L.; Jean, B.; Korey, M.; Nieh, W.; Ong, K. J. Current Characterization Methods for Cellulose Nanomaterials. Chem. Soc. Rev. 2018, 47 (8), 2609-2679. https://doi.org/10.1039/c6cs00895j. 
44. Islam, S.; Chen, L.; Sisler, J.; Tam, K. C. Cellulose Nanocrystal (CNC) - Inorganic Hybrid Systems: Synthesis, Properties and Applications. J. Mater. Chem. B 2018, 6 (6), 864-883. https://doi.org/10.1039/C7TB03016A.

45. Kim, Y.-J.; Uyama, H. Biocompatible Hydrogel Formation of Gelatin from Cold Water Fish via Enzymatic Networking. Polym. J. 2007, 39 (10), 1040-1046. https://doi.org/10.1295/polymj.PJ2007007.

46. Folk, J. E.; Finlayson, J. S. The Epsilon-(Gamma-Glutamyl)Lysine Crosslink and the Catalytic Role of Transglutaminases. Adv. Protein Chem. 1977, 31, 1-133.

47. Fuchsbauer, H. L.; Gerber, U.; Engelmann, J.; Seeger, T.; Sinks, C.; Hecht, T. Influence of Gelatin Matrices Crosslinked with Transglutaminase on the Properties of an Enclosed Bioactive Material Using $\beta$-Galactosidase as Model System. Biomaterials 1996, 17 (15), 1481-1488. https://doi.org/10.1016/0142-9612(96)89772-9.

48. Crescenzi, V.; Fancescangeli, A.; Taglienti, A. New Gelatin-Based Hydrogels via Enzymatic Networking. Biomacromolecules 2002, 3 (6), 1384-1391. https://doi.org/10.1021/bm025657m.

49. Babin, H.; Dickinson, E. Influence of Transglutaminase Treatment on the Thermoreversible Gelation of Gelatin. Food Hydrocoll. 2001, 15 (3), 271-276. https://doi.org/10.1016/S0268005X(01)00025-X.

50. Yung, C. W.; Wu, L. Q.; Tullman, J. A.; Payne, G. F.; Bentley, W. E.; Barbari, T. A. Transglutaminase Crosslinked Gelatin as a Tissue Engineering Scaffold. J. Biomed. Mater. Res. Part A 2007, 83A (4), 1039-1046. https://doi.org/10.1002/jbm.a.31431. 
51. Myrovali, E.; Maniotis, N.; Makridis, A.; Terzopoulou, A.; Ntomprougkidis, V.; Simeonidis, K.; Sakellari, D.; Kalogirou, O.; Samaras, T.; Salikhov, R.; et al. Arrangement at the Nanoscale: Effect on Magnetic Particle Hyperthermia. Sci. Rep. 2016, 6 (1), 37934. https://doi.org/10.1038/srep37934.

52. Hao, S.; Zhang, Y.; Meng, J.; Liu, J.; Wen, T.; Gu, N.; Xu, H. Integration of a Superparamagnetic Scaffold and Magnetic Field To Enhance the Wound-Healing Phenotype of Fibroblasts. ACS Appl. Mater. Interfaces 2018, 10 (27), 22913-22923. https://doi.org/10.1021/acsami.8b04149.

53. Yun, H. M.; Ahn, S. J.; Park, K. R.; Kim, M. J.; Kim, J. J.; Jin, G. Z.; Kim, H. W.; Kim, E. C. Magnetic Nanocomposite Scaffolds Combined with Static Magnetic Field in the Stimulation of Osteoblastic Differentiation and Bone Formation. Biomaterials 2016, 85, 88-98. https://doi.org/10.1016/j.biomaterials.2016.01.035.

54. Gonçalves, A. I.; Rodrigues, M. T.; Carvalho, P. P.; Bañobre-López, M.; Paz, E.; Freitas, P.; Gomes, M. E. Exploring the Potential of Starch/Polycaprolactone Aligned Magnetic Responsive Scaffolds for Tendon Regeneration. Adv. Healthc. Mater. 2016, 5 (2), 213-222. https://doi.org/10.1002/adhm.201500623.

55. Jaiswal, M. K.; Xavier, J. R.; Carrow, J. K.; Desai, P.; Alge, D.; Gaharwar, A. K. Mechanically Stiff Nanocomposite Hydrogels at Ultralow Nanoparticle Content. ACS Nano 2016, 10 (1), 246-256. https://doi.org/10.1021/acsnano.5b03918.

56. Peña, B.; Laughter, M.; Jett, S.; Rowland, T. J.; Taylor, M. R. G.; Mestroni, L.; Park, D. Injectable Hydrogels for Cardiac Tissue Engineering. Macromol. Biosci. 2018, 18 (6), 1800079. https://doi.org/10.1002/mabi.201800079. 
57. Cukierman, E. Taking Cell-Matrix Adhesions to the Third Dimension. Science (80-. ). 2001, 294 (5547), 1708-1712. https://doi.org/10.1126/science.1064829.

58. Yeung, T.; Georges, P. C.; Flanagan, L. A.; Marg, B.; Ortiz, M.; Funaki, M.; Zahir, N.; Ming, W.; Weaver, V.; Janmey, P. A. Effects of Substrate Stiffness on Cell Morphology, Cytoskeletal Structure, and Adhesion. Cell Motil. Cytoskeleton 2005, 60 (1), 24-34. https://doi.org/10.1002/cm.20041.

59. Torbet, J.; Dickens, M. J. Orientation of Skeletal Muscle Actin in Strong Magnetic Fields. FEBS Lett. 1984, 173 (2), 403-406. https://doi.org/10.1016/0014-5793(84)80814-5.

60. Iwasaka, M.; Miyakoshi, J.; Ueno, S. Magnetic Field Effects on Assembly Pattern of Smooth Muscle Cells. Vitr. Cell. Dev. Biol. - Anim. 2003, 39 (3-4), 120-123. https://doi.org/10.1007/s11626-003-0005-0.

61. Coletti, D.; Teodori, L.; Albertini, M. C.; Rocchi, M.; Pristerà, A.; Fini, M.; Molinaro, M.; Adamo, S. Static Magnetic Fields Enhance Skeletal Muscle Differentiation in Vitro by Improving Myoblast Alignment. Cytom. Part A 2007, 71 (10), 846-856. https://doi.org/10.1002/cyto.a.20447. 


\section{Injectable and magnetic responsive hydrogels with bioinspired ordered structures}

Sandra Araújo-Custódio, Manuel Gomez-Florit, Ana R. Tomás, Bárbara B. Mendes, Pedro S.

Babo, Suzanne M. Mithieux, Anthony Weiss, Rui M. A. Domingues*, Rui L. Reis and Manuela E.

\section{Gomes*}

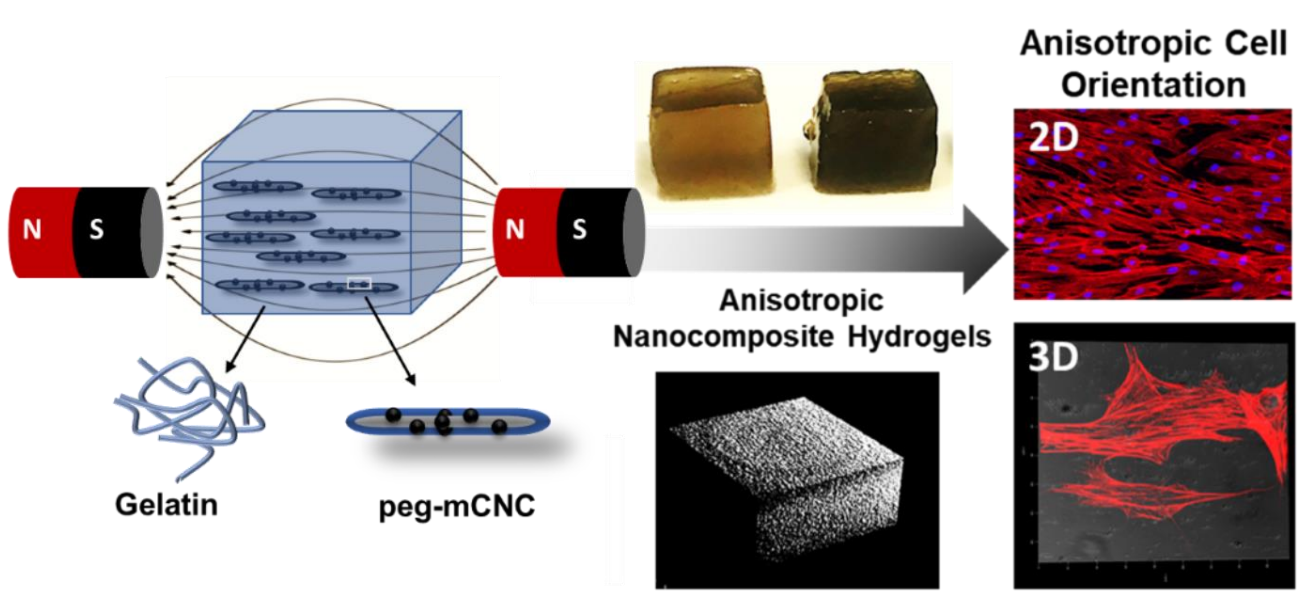

